Article

\title{
Comparison of the Economy and Controllability of Pressure Swing Distillation with Two Energy-Saving Modes for Separating a Binary Azeotrope Containing Lower Alcohols
}

\author{
Liping Lv ${ }^{1,2}$, Hang $\mathrm{Li}^{2}$, Zheng Zhang ${ }^{3, *}$ and Huisheng Huang ${ }^{1}$ \\ 1 School of Chemistry and Chemical Engineering, Yangtze Normal University, Fuling 408100, China; \\ lvliping@yznu.edu.cn (L.L.); h.s.huang@hotmail.com (H.H.) \\ 2 Key Laboratory of Gas Process Engineering, School of Chemistry and Chemical Engineering, Southwest \\ Petroleum University, Chengdu 610500, China; lihang0213@163.com \\ 3 China Petroleum Engineering \& Construction Corporation Southwest Company, Chengdu 610041, China \\ * Correspondence: zhangzheng_sw@cnpc.com.cn
}

Received: 30 July 2019; Accepted: 8 October 2019; Published: 12 October 2019

check for updates

\begin{abstract}
The pressure swing distillation (PSD) with two different energy-saving modes are put forward to separate a binary azeotrope containing lower alcohols: benzene/methanol. A comparison of the economy and controllability for the partial and fully heat integrated pressure swing distillation (HIPSD) is made by detailed simulation analysis. The optimal operating parameters of partial and fully HIPSD processes are obtained by minimizing total annual cost (TAC). These results show that the fully HIPSD mode saves 5.88\% TAC compared with the partial HIPSD mode. Meanwhile, this paper proposes that the composition slope profile can help to select the temperature control stage (TCS), when the temperature profile in the column is rising rapidly near the bottom and the maximum of temperature slope value occurs in the bottom of the column. Several control structures are developed to check the rationality of the selection of the TCS and evaluate the industrial application. These results illustrate the composition/temperature cascade control structure for the PSD with two energy-saving modes can both get good control performances, and the purities of benzene and methanol can be brought close back to the initial value. However, the fully HIPSD mode can only handle much smaller composition disturbances $(<10 \%)$ compared with the partial HIPSD mode. Therefore, the selection of energy-saving modes for the separation process should weigh economy against controllability.
\end{abstract}

Keywords: economy; controllability; pressure swing distillation; azeotrope; benzene/methanol

\section{Introduction}

Several binary azeotropic systems containing low carbon alcohols, such as benzene and methanol, are widely used in the chemical and petrol chemical industries [1-3]. To separate and recycle the azeotropic mixture, several enhanced distillations including pressure swing distillation (PSD) [4-6], azeotropic distillation (AD) [7,8], and extractive distillation (ED) [9-11] have been applied to separate the azeotrope successfully. For example, Shen et al. put emphasis on the separation of azeotropic systems for the ED method [12]. Shirsat and Wang et al. optimized the ED and PSD method of separating the isobutyl alcohol/isobutyl acetate and tetrahydrofuran/ethanol azeotropic system, and indicated that the cost and product contamination should be concerned when selecting the separation method $[13,14]$. Compared with AD and ED methods, PSD has drawn more and more attention for the benefit of no third component added into the azeotropic system. Fulgueras and Maloney [15] pointed out that PSD method was economically feasible when the mass fraction of azeotropic composition 
changed more than $5 \%$ ( $10 \%$ is better) in the range of pressure 10 bar. The PSD process has two columns which includes low pressure column (LPC) and high pressure column (HPC). For the minimum boiling azeotropes, the high-purity component can be obtained at the bottom of LPC and HPC. For the maximum boiling azeotropes, the opposite is true.

To reduce heating and cooling loads of thermal utilities and improve heat recovery capacity of the system, some methods such as heat integration are proposed. In general, two modes of heat integration are usually applied in the internal system $[6,16,17]$. One mode is the heat integration between condenser and reboiler, which includes partial and fully heat integration. The heat integration between the rectifying and stripping section is another mode. In the past years, the economy of PSD processes was compared with different heat integrated modes [1,18,19]. Luyben [1] explored the separation of tetrahydrofuran/water azeotropic system by PSD method with two different heat integrated modes. Wang et al. [19] made a comparison of partial and fully heat integrated pressure swing distillation (HIPSD) modes for the separation of methanol/tetrahydrofuran azeotropic system. These results show that the economy of the PSD process depends on the different azeotropic systems and heat-integrated modes.

Not only the economy but also the controllability of the separation process should be considered in the determination of a suitable separation method. Many researchers pointed out that the economy of the fully HIPSD mode was better but the controllability was weaker than that of the partial HIPSD mode $[1,17,19]$. The main reason is that the distillate stream of the HPC is used to provide the heat source of the reboiler in the LPC and no auxiliary reboiler is needed, leading to a degree of freedom missed in the full HIPSD process. Luyben [1] studied the energy consumption and controllability of partial and fully HIPSD modes for the separating water/tetrahydrofuran azeotropic system. It was revealed that the energy consumption for the fully HIPSD mode was lowest among the three heat integration modes, but its dynamic controllability was worse compared with the other two heat integration modes. As a result, it is necessary to weigh the energy consumption and controllability for different heat integrated modes. Zhang et al. explored the separation of a methyl acetate/methanol azeotropic system by different heat-integrated modes. It can be seen that the fully HIPSD mode has a little economic benefit compared with partial HIPSD mode, but its controllable performance is also poor [6]. Zhu et al. contrasted the economics and controllability for separating of ethanol and toluene azeotropic system by PSD process with three modes of heat integration [3]. The results indicated that the total annual cost (TAC) for the fully heat integration is lowest, but this kind of heat integration mode can handle only small disturbances very well. Similar studies were done for separating an n-butyl alcohol and toluene system [20], a methanol and tetrahydrofuran system [2], and an ethanol and chloroform system [21].

The selection of the temperature control stage (TCS) is very important to achieve the excellent control performance because the signal of TCS is detected by the temperature controller and transmitted to the adjusted variable. In general, five criteria including product fluctuation minimum criterion, constant temperature criterion, singular value decomposition, sensitivity criterion, and slope criterion are usually used to select the suitable TCS. Zhang et al. used singular value decomposition and sensitivity criterion to select the TCS [6]. Hosgor et al. explored the separation of the chloroform/methanol azeotropic system by fully HIPSD process and used slope criterion to select the TCS [22]. Zhang et al. presented a derivative slope criterion to choose the TCS when the temperature distribution is quite close to linear [23].

So far, there has been no article published that compares PSD with different heat integrated modes for separating benzene/methanol azeotrope through economy and controllability angles. In this work, the feasibility of the PSD process with two energy-saving modes for the separation of the benzene/methanol azeotrope were proved, and a comparison of the economy and controllability for the partial and fully HIPSD process were made in detail. Firstly, the partial and fully HIPSD processes were optimized based on the minimization of the TAC. Secondly, a composition slope criterion was presented to assist the selection of the suitable TCS for the HPC, when the temperature distribution in 
the column is rising rapidly near the bottom and the maximum of temperature slope value occurs in the bottom of the column. The different degrees of the disturbance in the feed flowrate and composition were introduced to verify the rationality of the selection of TCS and evaluate the industrial application of two processes.

\section{Steady State Design and Optimization}

\subsection{Property Method}

The accuracy of the steady-state simulation depends on the selection of the thermodynamic model. Since the benzene/methanol azeotrope is a strongly non-ideal system, several thermodynamic models including Wilson, NRTL and UNIQUAC equations are used for calculating the vapor-liquid equilibrium (VLE) data at 1 bar. The average relative error between calculated and experimental data is listed in the Table 1. As seen from this table, the average relative error of the Wilson equation is minimum. Figure 1 shows the T-x-y diagram of benzene/methanol azeotropic system with experimental data and calculated data at 1 bar. From Figure 1, the calculated data and experimental data are in good agreement. Therefore, the Wilson equation was selected as the suitable property method.

Table 1. The error analysis of the thermodynamic models.

\begin{tabular}{cccc}
\hline Thermodynamic Models & Wilson & NRTL & UNIQUAC \\
\hline Average relative error $/ \%$ & 0.9295 & 2.247 & 1.8563 \\
\hline
\end{tabular}

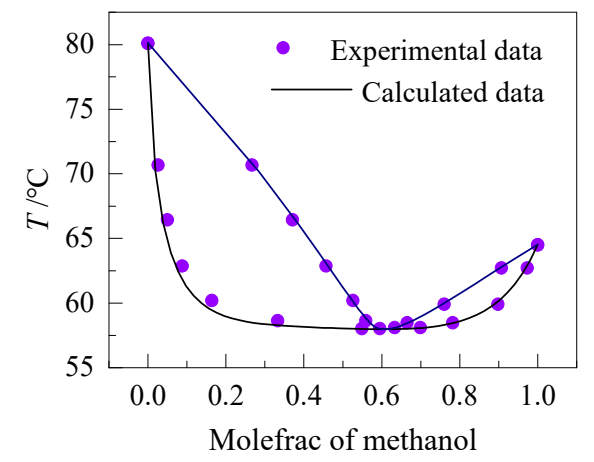

Figure 1. T-x-y diagram of benzene/methanol system with experimental data and calculated data at 1 bar.

\subsection{Optimization Method}

TAC including both equipment cost and annual operating cost is a common measure for the economic evaluation in chemical and pharmaceutical process [18]. Equations (1)-(3) show the detailed calculation. Note that the payback period time is set as 3 years and the operation time is set at 8000 $\mathrm{h} /$ year. The equipment cost for the partial and fully HIPSD processes mainly includes two distillation columns and heat exchangers. Compared with heat exchangers and distillation columns, the costs for the pumps, reflux drum, pipes and valves are very low, which can even be ignored in the conceptual design phase [18,24]. The diameters of HPC and LPC are computed via the "tray sizing" function in the Aspen plus. The annual operating cost mainly includes the annual steam cost and cooling water cost. The related calculating formulae and parameters are listed in the Table 2 according to previous work of Luyben and Douglas $[19,24]$.

$$
\mathrm{TAC}=\frac{\text { total equipment } \cos \mathrm{t}}{\text { payback period }}+\text { annual operating } \cos \mathrm{t},
$$

Total equipment cost $=$ distillation columns + heat exchangers cost, 
Annual operating cost $=$ annual steam cost + annual cooling water cost.

Table 2. Basis economics and equipment sizing.

\begin{tabular}{|c|c|c|}
\hline \multicolumn{2}{|c|}{ Parameters } & Data \\
\hline TAC & & $\begin{array}{c}\text { TAC }=\frac{\text { total equipment cost }}{\text { payback period }}+\text { annual operating cos } \mathrm{t} \\
\text { Payback period }=3 \text { years }\end{array}$ \\
\hline \multirow{8}{*}{ Total equipment cost } & Distillation column cost & Equipment cost $=17,640 \times(\mathrm{D}, \mathrm{m})^{1.066} \times(\mathrm{L}, \mathrm{m})^{0.802}$ \\
\hline & & Length: $\mathrm{H}=1.2 \times 0.61 \times\left(\mathrm{N}_{\mathrm{T}}-2\right)$ \\
\hline & Condensers or Condenser/Reboiler & Equipment cost $=7296 \times\left(\mathrm{Ac}, \mathrm{m}^{2}\right)^{0.65}$ \\
\hline & \multirow{5}{*}{ Reboilers } & Heat-transfer coefficient $\left(\mathrm{K}_{\mathrm{C}}\right)=0.852 \mathrm{~kW} / \mathrm{K} \cdot \mathrm{m}^{2}$ \\
\hline & & Heat transfer area: $A c=\frac{Q}{(K \times \Delta t)}$ \\
\hline & & Equipment cost $=7296 \times\left(\mathrm{Ac}, \mathrm{m}^{2}\right)^{0.65}$ \\
\hline & & Heat-transfer coefficient $\left(\mathrm{K}_{\mathrm{R}}\right)=0.568 \mathrm{~kW} / \mathrm{K} \cdot \mathrm{m}^{2}$ \\
\hline & & Heat transfer area: $A c=\frac{Q}{\left(K_{R} \times \Delta t\right)}$ \\
\hline \multirow{6}{*}{ Annual operating cost } & Annual stream cost & Annual stream cost $=\mathrm{Q} \times \mathrm{C}_{\mathrm{S}} \times 8000 \times 3600$ \\
\hline & & LP steam $\left(6\right.$ bar, $\left.160^{\circ} \mathrm{C}\right): \$ 7.78 / \mathrm{GJ}$ \\
\hline & & MP steam (11 bar, $\left.184^{\circ} \mathrm{C}\right): \$ 8.22 / \mathrm{GJ}$ \\
\hline & & HP steam (42 bar, $\left.254^{\circ} \mathrm{C}\right): \$ 9.88 / \mathrm{GJ}$ \\
\hline & Annual cooling water cost & Annual cooling water cost $=Q \times C_{c} \times 8000 \times 3600$ \\
\hline & & Cooling water: $\$ 0.354 / \mathrm{GJ}$ \\
\hline
\end{tabular}

\subsection{Pressure Determination}

Figure 2 displays the azeotropic composition and temperature in the pressure range of $0.1-10$ bar. From Figure 2, the variation of the azeotropic composition is about $50 \%$ when the pressure changes from 0.1 to 10 bar which sufficiently indicates that the PSD method for separating benzene/methanol azeotropic system is economic and feasible.

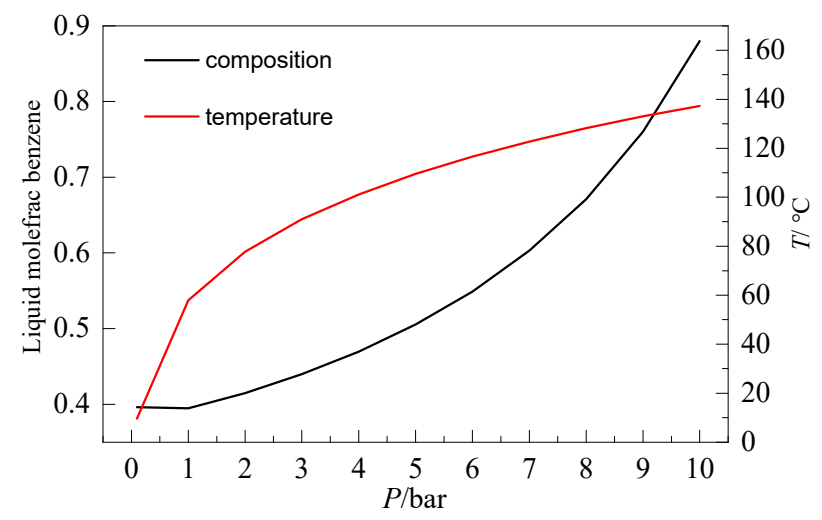

Figure 2. Effect of pressure on azeotropic composition and temperature.

Furthermore, the key of PSD is the selection of the pressures of two columns. The difference of azeotropic composition increases with the increase of pressure difference, which leads to decrease of the material circulation and energy consumption. However, it increases the cost of the equipment. For the LPC, the complexity and cost of the refrigeration system increase when the operating pressure is too low. In general, the pressure of the LPC is set as 1 bar, and the top vapor stream (about $57^{\circ} \mathrm{C}$ ) of the LPC can be condensed by the cooling water $\left(32^{\circ} \mathrm{C}\right)$. For the HPC, the selection principle of the pressure is that the top stream can be used to heat the bottom liquid stream of LPC [6,25]. Table 3 gives the TAC of several cases with different pressures in HPC. Note that the temperature difference between the bottom liquid stream (about $67^{\circ} \mathrm{C}$ at 1 bar) and the top vapor stream (about $116{ }^{\circ} \mathrm{C}$ at 6 bar) is more than $25^{\circ} \mathrm{C}$. Thus, the heat integration can be implemented in the internal system. From Table 3, the TAC is minimum for the HPC at 6 bar while the pressure of HPC at range of 7-10 bar. The main 
reason is that the equipment cost and operating cost have a significant increase when the operation pressure of HPC is greater than or equal to 7 bar. Therefore, the optimum operation pressure of HPC is selected as 6 bar.

Table 3. Case studies of pressure swing distillation (PSD) with partial heat integration.

\begin{tabular}{|c|c|c|c|c|c|}
\hline Variables & Case1 & Case2 & Case3 & Case4 & Case5 \\
\hline $\mathrm{P}_{1}$ (bar) & 1 & 1 & 1 & 1 & 1 \\
\hline $\mathrm{P}_{2}$ (bar) & 6 & 7 & 8 & 9 & 10 \\
\hline $\mathrm{N}_{\mathrm{T} 1} / \mathrm{N}_{\mathrm{T} 2}$ & $20 / 20$ & $20 / 20$ & $20 / 20$ & $20 / 20$ & $20 / 20$ \\
\hline $\mathrm{N}_{\mathrm{F} 1} / \mathrm{N}_{\mathrm{R}} / \mathrm{N}_{\mathrm{F} 2}$ & $10 / 6 / 14$ & $10 / 10 / 10$ & $11 / 7 / 12$ & $9 / 10 / 15$ & $10 / 10 / 10$ \\
\hline $\mathrm{RR}_{1} / \mathrm{RR}_{2}$ & $0.7 / 1$ & $1.5 / 2$ & $1.5 / 4$ & $1.3 / 2$ & $4 / 2$ \\
\hline $\mathrm{ID}_{1} / \mathrm{ID}_{2}$ & $0.437 / 0.394$ & $0.539 / 0.461$ & $0.529 / 0.538$ & $0.512 / 0.424$ & $0.623 / 0.260$ \\
\hline $\mathrm{R}_{\text {rec }}(\mathrm{kg} / \mathrm{h})$ & 987.597 & 829.923 & 770.849 & 770.094 & 450.316 \\
\hline $\mathrm{Q}_{\mathrm{C} 1} / \mathrm{Q}_{\mathrm{C} 2}$ & $-404.579 / 0$ & $-532.573 / 0$ & $-524.103 /-215.221$ & $-484.754 / 0$ & $-693.918 / 0$ \\
\hline $\mathrm{Q}_{\mathrm{R} 1} / \mathrm{Q}_{\mathrm{R} 2}$ & $39.144 / 410.218$ & $69.3 / 510.74$ & $0 / 789.316$ & $32.111 / 504.469$ & 439.747/307.238 \\
\hline Equipment cost $\left(10^{5} \$ / y\right)$ & 3.27084 & 3.88473 & 4.31063 & 3.65064 & 3.87671 \\
\hline Energy cost $\left(10^{5} \$ / y\right)$ & 1.04811 & 1.47438 & 1.92203 & 1.31563 & 1.78340 \\
\hline TAC $\left(10^{5} \$ / y\right)$ & 2.14079 & 2.76929 & 3.35891 & 2.53251 & 3.07564 \\
\hline
\end{tabular}

\subsection{Optimization}

\subsubsection{Optimization of Distillation Sequence}

For the partial and fully HIPSD processes, the distillation sequence including LP-HP and HP-LP should be first determined via the minimization of the TAC. For the LP-HP distillation sequence, the raw material which contains $70 \mathrm{wt} \%$ methanol and $30 \mathrm{wt} \%$ benzene is first fed into the LPC. The methanol product is obtained in the bottom of LPC and the azeotropic mixture of benzene and methanol is fed to the HPC. The bottom product of the HPC is the high-purity benzene. The top azeotrope in HPC is used as the heat sources of LPC reboiler and then recycled to the LPC. For the HP-LP distillation sequence, the first column is HPC and the second column is LPC. When the raw material with same composition is fed in the HPC, the high-purity methanol product is first obtained at the bottom of the first column and the high-purity benzene is produced at the bottom of the second column. Table 4 lists the economic comparison for partial and fully HIPSD processes with different distillation sequences. The results indicate that the former one is more economical than the latter one for the partial and fully HIPSD processes.

Table 4. Economic comparison for partial and fully heat integrated pressure swing distillation (HIPSD) processes with different distillation sequences.

\begin{tabular}{ccccc}
\hline \multirow{2}{*}{ Variables } & \multicolumn{2}{c}{ Partial HIPSD } & \multicolumn{2}{c}{ Fully HIPSD } \\
\cline { 2 - 5 } & LP-HP & HP-LP & LP-HP & HP-LP \\
\hline $\mathrm{P}_{1}$ (bar) & 1 & 6 & 1 & 6 \\
$\mathrm{P}_{2}$ (bar) & 6 & 1 & 6 & 1 \\
$\mathrm{~N}_{\mathrm{T} 1} / \mathrm{N}_{\mathrm{T} 2}$ & $20 / 20$ & $20 / 20$ & $19 / 21$ & $20 / 20$ \\
$\mathrm{~N}_{\mathrm{F} 1} / \mathrm{N}_{\mathrm{R}} / \mathrm{N}_{\mathrm{F} 2}$ & $10 / 6 / 14$ & $6 / 16 / 10$ & $12 / 9 / 14$ & $6 / 16 / 10$ \\
$\mathrm{RR}_{1} / \mathrm{RR}_{2}$ & $0.7 / 1$ & $2 / 1.5$ & $0.61 / 1.097$ & $2 / 3.768$ \\
$\mathrm{ID}_{1} / \mathrm{ID}_{2}$ & $0.437 / 0.394$ & $0.858 / 0.663$ & $0.313 / 0.4$ & $0.773 / 0.912$ \\
$\mathrm{R}_{\mathrm{rec}}(\mathrm{kg} / \mathrm{h})$ & 987.597 & 1703.14 & 971.051 & 1664.69 \\
$\mathrm{Q}_{\mathrm{C} 1} / \mathrm{Q}_{\mathrm{C} 2}$ & $-404.579 / 0$ & $-662.357 /-784.539$ & $-376.467 /-348.977$ & $-1320.5 /-1462.78$ \\
$\mathrm{Q}_{\mathrm{R} 1} / \mathrm{Q}_{\mathrm{R} 2}$ & $39.144 / 410.218$ & $1494.72 / 662.357$ & $348.977 / 421.276$ & $1509.54 / 1320.51$ \\
Equipment cost $\left(10^{5} \$ / \mathrm{y}\right)$ & 3.27084 & 6.20901 & 2.53782 & 5.94179 \\
Energy cost $\left(10^{5} \$ / \mathrm{y}\right)$ & 1.04811 & 3.49664 & 0.98231 & 3.09342 \\
TAC $\left(10^{5} \$ / \mathrm{y}\right)$ & 2.14079 & 5.56631 & 1.82825 & 5.07401 \\
\hline
\end{tabular}

\subsubsection{Optimization of Operating Parameters}

For the partial HIPSD mode, the extra energy needs to be supplied (removed) by an auxiliary reboiler (condenser) since the heat duty of reboiler for $L P C\left(Q_{R 1}\right)$ is not equal to the heat duty of 
condenser for $\mathrm{HPC}\left(\mathrm{Q}_{\mathrm{C} 2}\right)$. When the material composition and the operating pressures are fixed, there are still several variables including the number of stages in LPC and HPC $\left(\mathrm{N}_{\mathrm{T} 1}\right.$ and $\left.\mathrm{N}_{\mathrm{T} 2}\right)$, and the feed positions $\left(\mathrm{N}_{\mathrm{F} 1}, \mathrm{~N}_{\mathrm{F} 2}, \mathrm{~N}_{\mathrm{R}}\right)$ and the reflux ratios of the LPC and $\mathrm{HPC}\left(\mathrm{RR}_{1}\right.$ and $\left.\mathrm{RR}_{2}\right)$ need to be optimized via set the minimum TAC as the objective function. The purities of the benzene and methanol as the constraint variables are set as $99.9 \mathrm{wt} \%$ via the "design specification/vary" function whose manipulating variables is the distillate to feed ratios of two columns. Figure 3 shows the sequential iterative optimization procedure for partial HIPSD process. From this figure, $R_{1}$ and $R_{2}$ are the innermost loops, $\mathrm{N}_{\mathrm{F} 1}, \mathrm{~N}_{\mathrm{F} 2}$, and $\mathrm{N}_{\mathrm{R}}$ are the secondary loops, and $\mathrm{N}_{\mathrm{T} 1}$ and $\mathrm{N}_{\mathrm{T} 2}$ are the outermost loops. The optimized operating parameters are acquired through multiple iterations of the internal cycle to external cycle parameter.

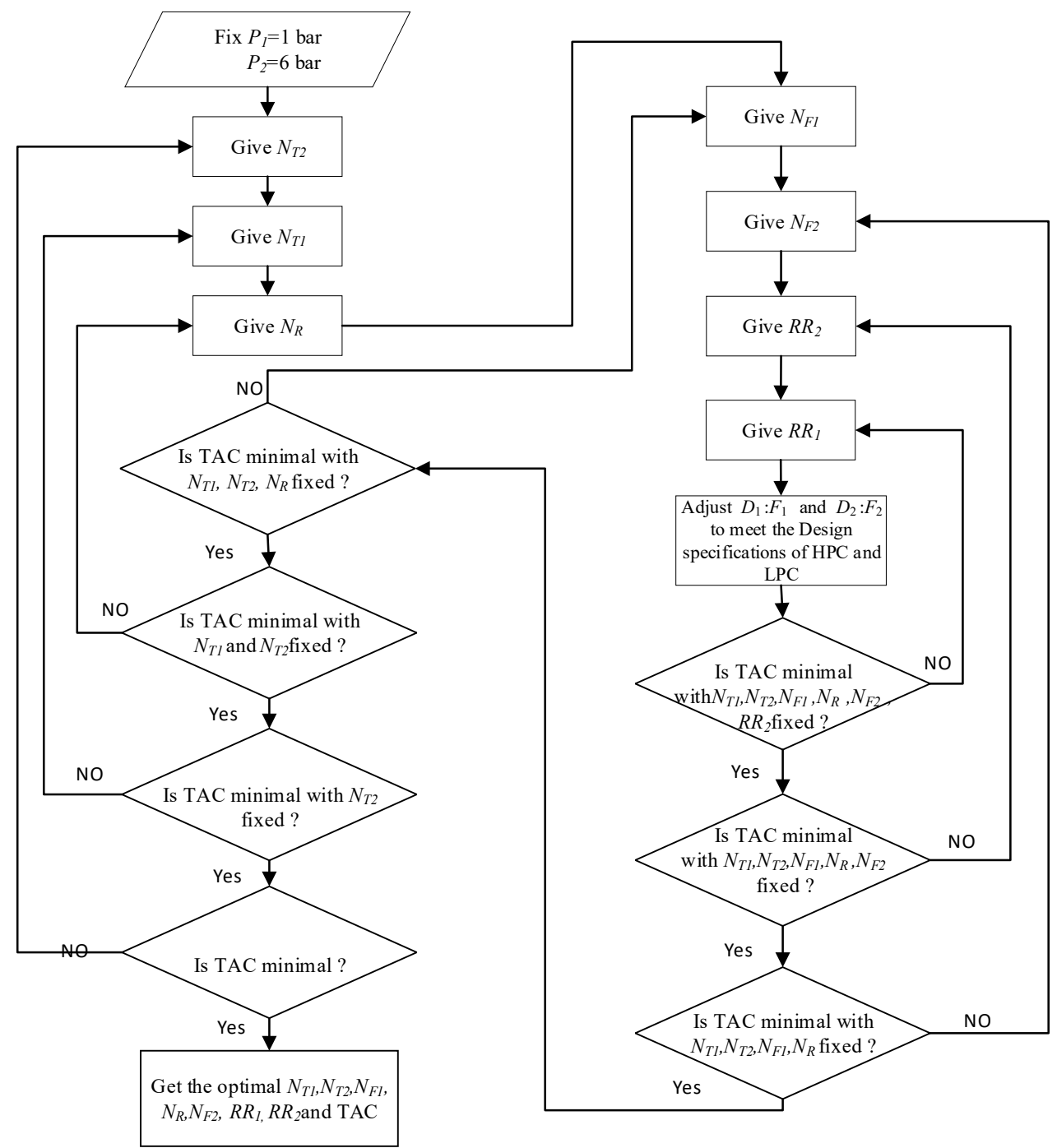

Figure 3. Sequential iterative optimization procedure for the partial HIPSD process.

Figure 4 shows the effect of the seven variables on TAC in the partial HIPSD process. As can be seen in these figures, the effects of each variable on TAC was first decrease then increase within limits. The detailed operating parameters and equipment parameters for the partial HIPSD process is displayed in Figure 5. From this figure, about $331.283 \mathrm{~kW}$ energy to the base of the LPC is supplied by the top vapor stream of the HPC and the extra $39.871 \mathrm{~kW}$ energy is supplied by the low-pressure steam to remain the energy requirement. The TAC of the partial HIPSD process is $\$ 198,891$. Compared with the no heat integrated PSD process, the equipment cost and annual energy cost of this process have saved $\$ 48,503$ and $\$ 77,607$, respectively. 
Compared with the partial HIPSD mode, there is no auxiliary reboiler needed in the fully HIPSD mode. The primary reason is that the top vapor stream of the HPC just can provide the required energy of the reboiler of LPC. Only one heat exchanger serves as the condenser and reboiler of two columns. In order to make the $-Q_{C 1}$ equal to $Q_{R 2}$, the $R_{2}$ is varied to implement the fully heat integration. Meanwhile, the distillate to feed ratios of HPC and LPC are adjusted to maintain the specific purities. The number of the variables in this process is less than the partial HIPSD process. The six variables including $\mathrm{N}_{\mathrm{T} 1}, \mathrm{~N}_{\mathrm{T} 2}, \mathrm{~N}_{\mathrm{F} 1}, \mathrm{~N}_{\mathrm{F} 2}, \mathrm{~N}_{\mathrm{R}}$, and $\mathrm{RR}_{1}$ should be optimized to obtain the best configuration by minimizing TAC. The optimization procedure and detailed optimizing flowsheet for the fully HIPSD mode are displayed in the Figures 6 and 7. The results indicate that the fully HIPSD process with a TAC of $\$ 187,189$ has more economic benefit than the partial HIPSD process.

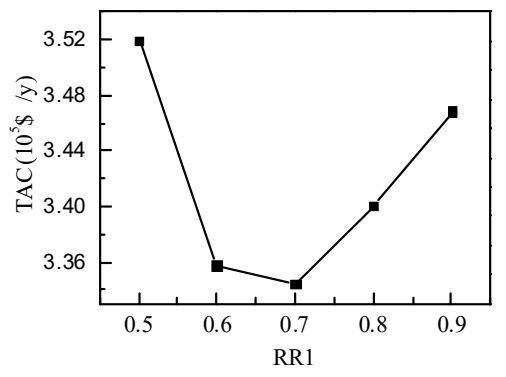

(a)

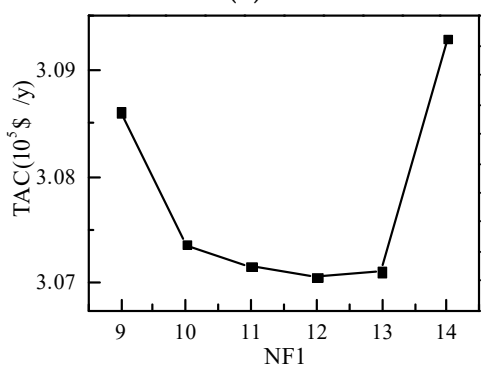

(c)

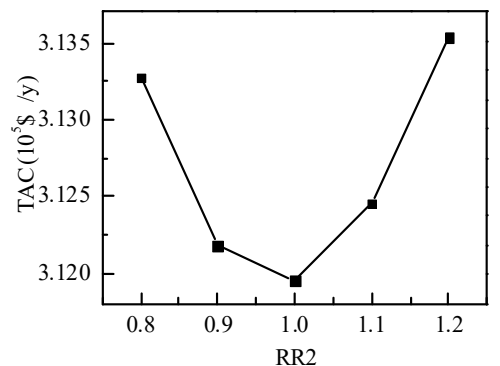

(b)

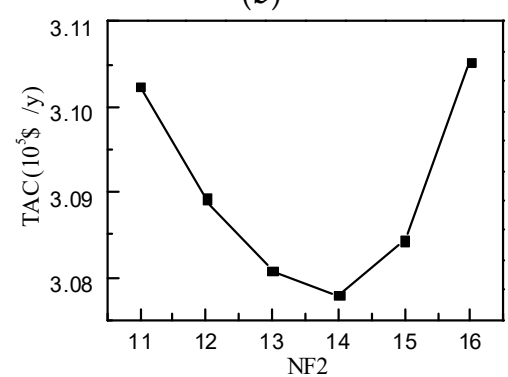

(d)

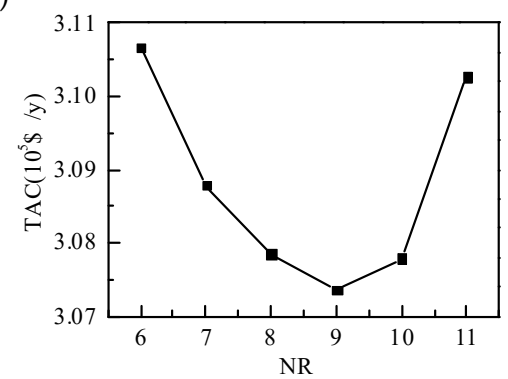

(e)

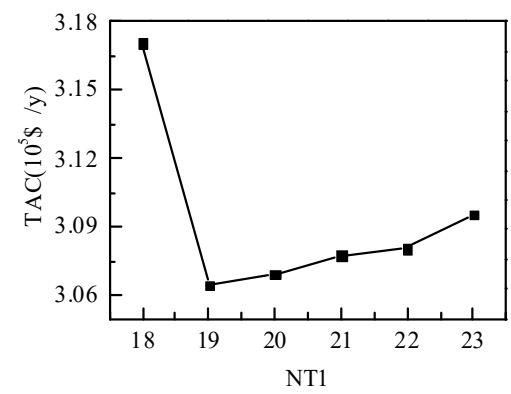

(f)

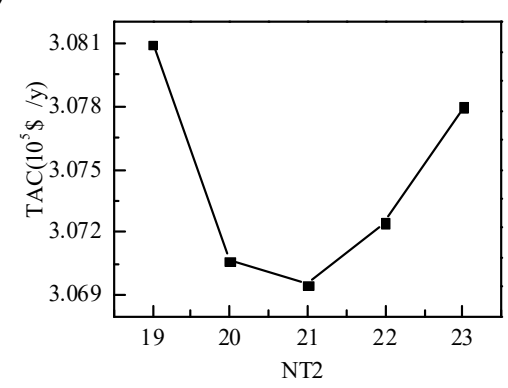

(g)

Figure 4. The effect of the seven variables on total annual cost (TAC) in the partial HIPSD process: (a) RR1, (b) RR2, (c) NF1, (d) NF2, (e) NR, (f) NT1, (g) NT2. 


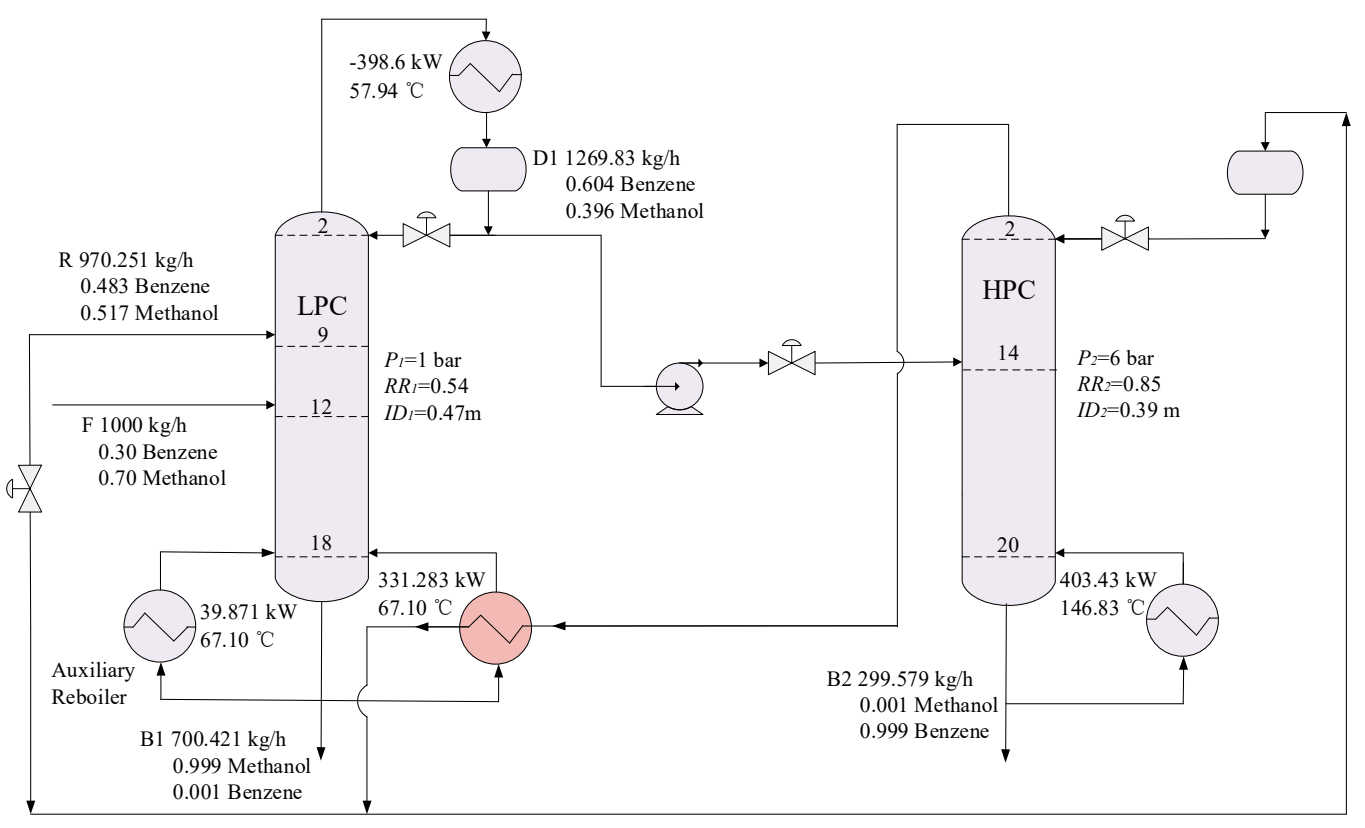

Figure 5. Flowsheet of the best optimal partial HIPSD process.

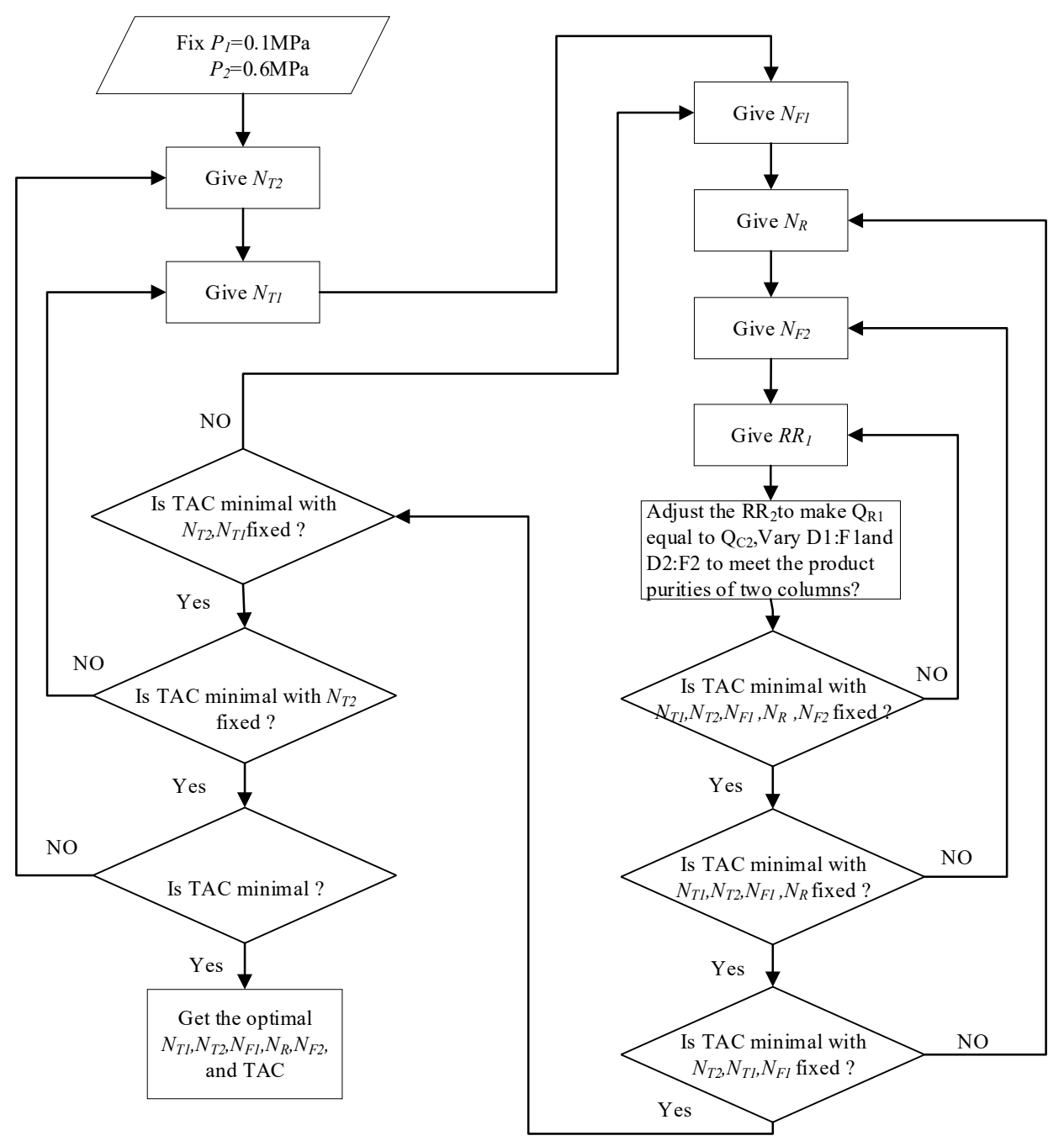

Figure 6. Sequential iterative optimization procedure for the fully HIPSD process. 


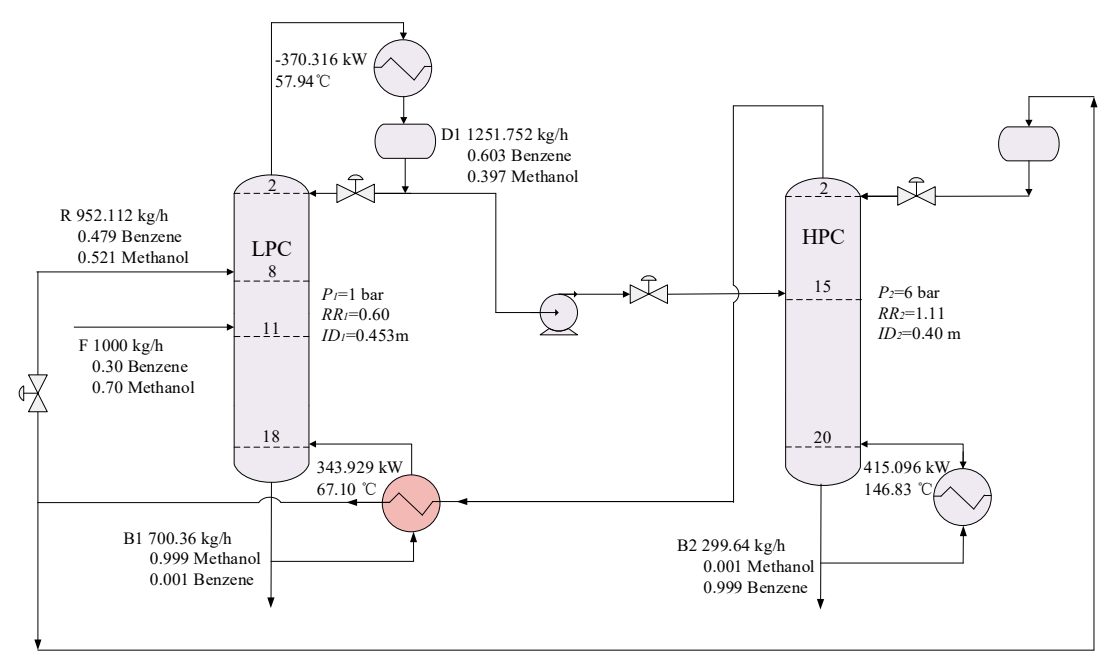

Figure 7. Flowsheet of the best optimal fully HIPSD process.

\section{Control Structure Design}

\subsection{Selection of TCS}

The selection of TCS is very important to keep the product purity at the specific value. Figure 8 shows the temperature distribution and the temperature slope distribution for the LPC and HPC. From the temperature distributions of two columns, the temperature increases quickly in the rectification section of two columns because the benzene and methanol build up near the bottom. According to the slope criterion by Luyben [24], there is one peak at stage 13 in the temperature slope distribution for LPC, and stage 13 is selected as the suitable TCS. For the HPC, the maximum value of the temperature slope is stage 21 which is the bottom of this column. In theory, the product purity can be achieved by keeping the temperature constant in the top or bottom of a distillation column. However, in reality, if the 21st stage is chosen as TCS, it will be very difficult to maintain the temperature as a constant value. The main reason is that the product stream of benzene is removed from the bottom of HPC where the temperature changes very quickly.
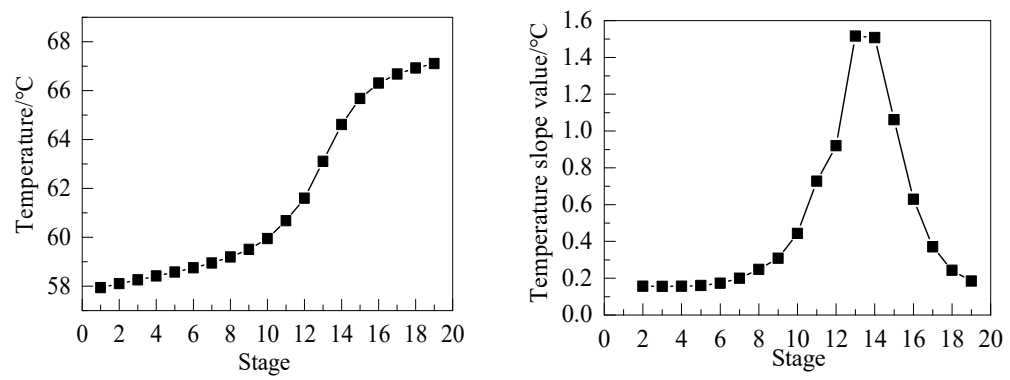

(a)
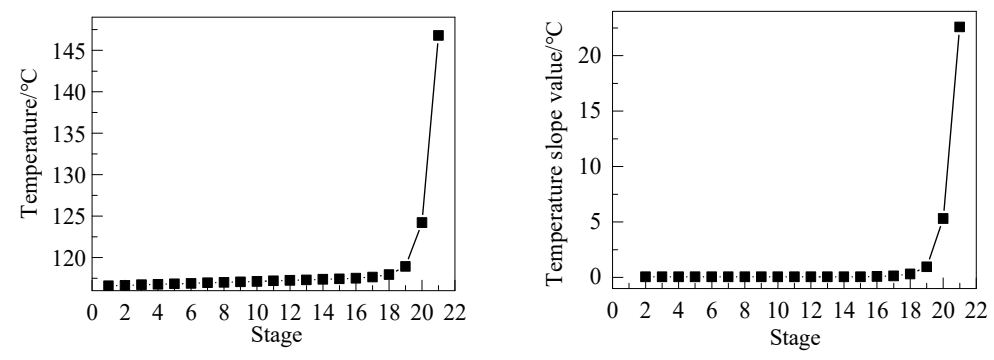

(b)

Figure 8. Temperature distribution and their slope distribution: (a) high pressure column (HPC), (b) low pressure column (LPC). 
The principle of selecting TCS based on slope criterion is that the temperature difference between two adjacent plates and the composition variation of key component correspond, one by one [24]. Therefore, this paper proposes that the composition and its slope profile can be used to assist the selection for the TCS. Figure 9 displays the composition distribution and its slope distribution of the HPC. From this figure, only one fairly sharp composition break appears on stage 20. Meanwhile, as can be seen in Figure 8b, the temperature slope value of stage 20 is the maxima, when removing the value of the temperature slope on stage 21. In summary, stage 20 in the HPC is selected as the temperature sensitive plate. In the next section, the rationality of selecting temperature sensitive plate will be confirmed by introducing the different degree disturbances with flowrate and composition in the control structures.
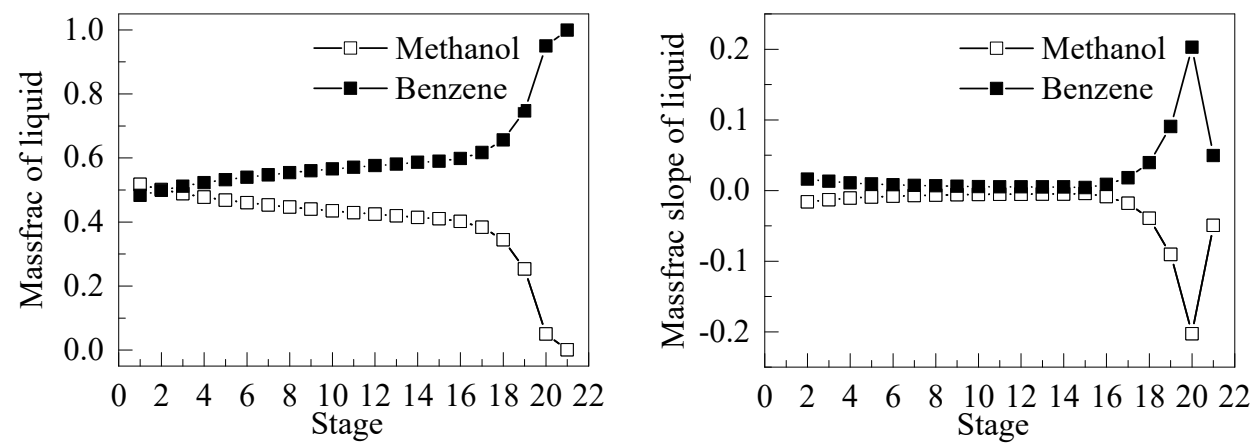

Figure 9. Composition distribution and its slope distribution of HPC.

\subsection{Control Strategies for Partial HIPSD Process}

\subsubsection{Control Structure CS1}

The dynamic characteristics of the partial HIPSD process was studied after optimizing the steady-state process. Under the heuristic method [24], the size of the reflux tank and bottom sump should be computed and entered into the "Dynamics/ Reflux drum and sump". The volumes of the reflux tank and bottom sump are calculated by Equation (4), the $\mathrm{q}_{\mathrm{v}}$ is the volume flow which is obtained by the "Profile/Hydraulics/volume flow liquid from stage 1", and the time of liquid holdup is $10 \mathrm{~min}$ to make them $100 \%$ full. In general, the ratio of length (or height) to diameter is set as 2 . Table 5 lists the size of devices in partial HIPSD process. Besides, the pressure drop of the control valve is set to 3 bar when the valve opening is $50 \%$. Note that the outlet pressure of all control valves must be equal to the pressure of the feed position.

$$
\mathrm{V}=10 \times 60 \times \mathrm{q}_{\mathrm{v}}
$$

Table 5. The size of devices for the partial HIPSD process.

\begin{tabular}{cccc}
\hline & Equipment & Low Pressure Column & High Pressure Column \\
\hline \multirow{3}{*}{ Reflux tank } & Volume flow $\left(\mathrm{m}^{3} / \mathrm{s}\right)$ & 0.000722942 & 0.00073135 \\
& Volume $\left(\mathrm{m}^{3}\right)$ & 0.434 & 0.439 \\
& Diameter/length $(\mathrm{m})$ & $0.65 / 1.30$ & $0.65 / 1.31$ \\
\hline \multirow{3}{*}{ Sump } & Volume flow $\left(\mathrm{m}^{3} / \mathrm{s}\right)$ & 0.000720035 & 0.00138284 \\
& Volume $\left(\mathrm{m}^{3}\right)$ & 0.432 & 0.830 \\
& Diameter/length $(\mathrm{m})$ & $0.65 / 1.30$ & $0.81 / 1.62$ \\
\hline
\end{tabular}

The basic control structure of the partial HIPSD process is built after checking the pressure of the steady-state flowsheet. The corresponding flowsheet, control panels, and the flowsheet equation are shown in the Figure 10. It can be seen that four kinds of controller including flow controller, pressure 
controller, level controller, and temperature controller are used in the flowsheet. For the LPC, the feed flowrate is controlled by flow controller. The levels of the reflux rank and the sump are kept by adjusting the stream flowrate of the top and sump. The pressure is controlled by adjusting the heat removal rate of the condenser. The temperature of the 13th stage is adjusted by the heat duty of the auxiliary reboiler in the LPC. However, for the HPC, the pressure controller has only a display function because the pressure is floating as the different operating condition, and the temperature controller TC2 is used to control the temperature of the 20th stage by adjusting the heat duty of the reboiler. In addition, two lag time modules with $1 \mathrm{~min}$ are embedded in the temperature control loops. According to the Tyreus-Luyben tuning by Luyben [24], the tuning parameters of TC1 and TC2 are determined by the relay-feedback rules. The relevant tuning results are given in Table 6.

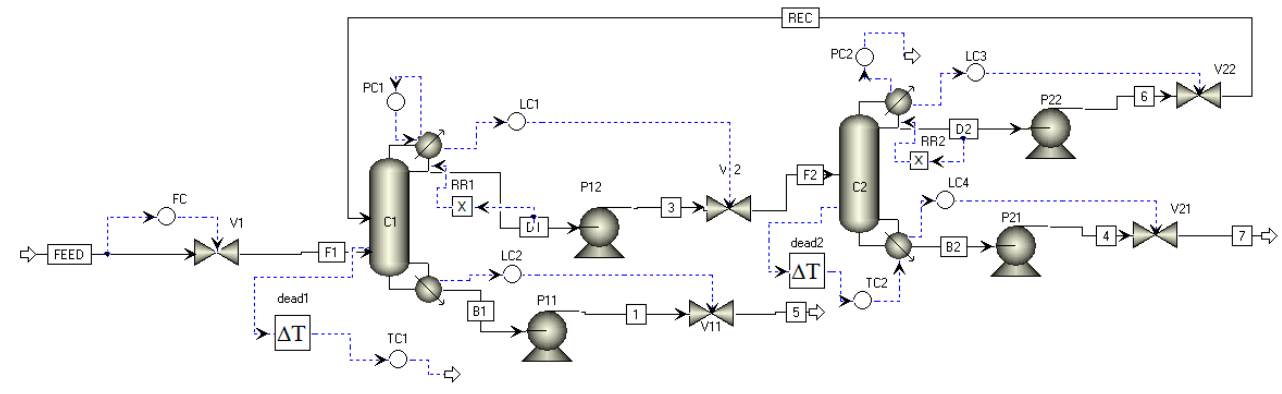

(a) Control structure CS1

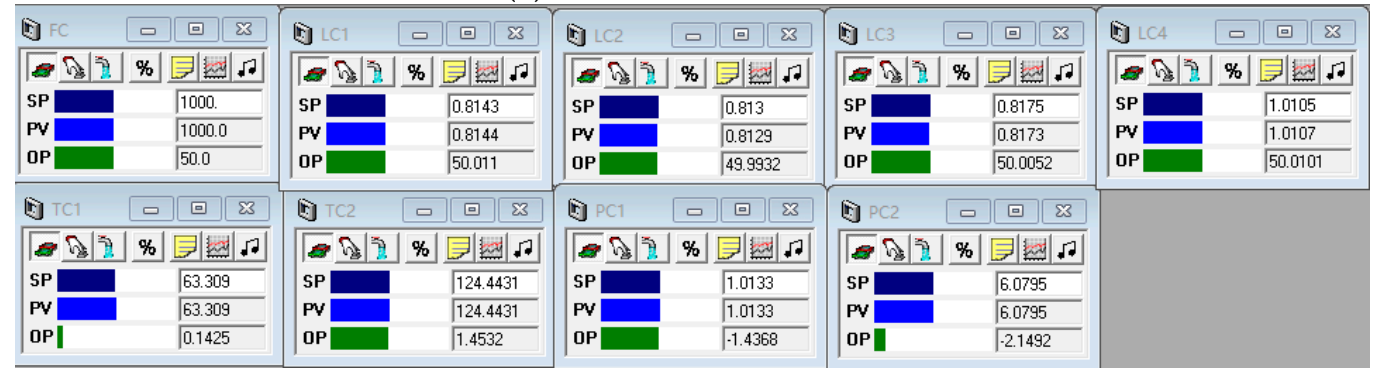

(b) control panels

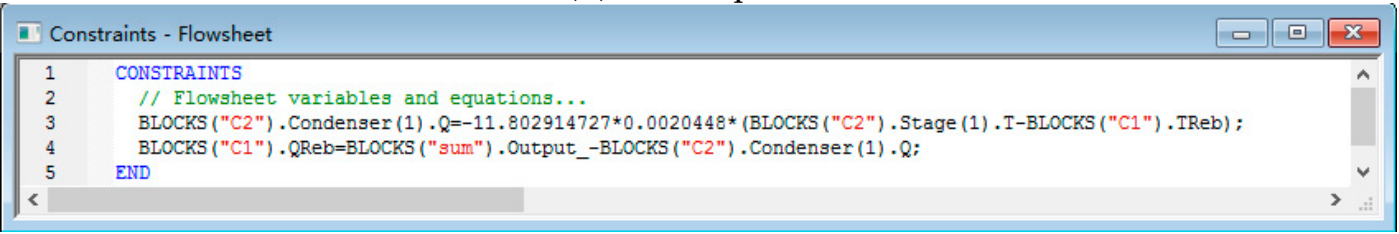

(c) Flowsheet equations

Figure 10. Control structure CS1, control panels, and flowsheet equations for the partial HIPSD process.

Table 6. Tuning parameters of temperature controllers TC1 and TC2.

\begin{tabular}{ccc}
\hline Parameter & TC1 & TC2 \\
\hline Control variable & $\mathrm{T}_{1,13}$ & $\mathrm{~T}_{2,20}$ \\
Operational variable & $\mathrm{Q}_{\mathrm{AR} 1}$ & $\mathrm{Q}_{\mathrm{R} 2}$ \\
Control variable range $/{ }^{\circ} \mathrm{C}$ & $0-126.62$ & $0-248.89$ \\
Operating variable range/GJ/h & $0-0.285$ & $0-2.91$ \\
Final gain/\%/\% & 15.36 & 10.02 \\
Final cycle/min & 3.6 & 3.6 \\
Gain/\%/\% & 4.80 & 3.13 \\
Integration time/min & 7.92 & 7.92 \\
\hline
\end{tabular}


In order to implement the partial HIPSD, some flowsheet equations used for calculating the heat duty of the composable condenser/reboiler $\left(\mathrm{Q}_{\mathrm{C} / \mathrm{R}}\right)$ and $\mathrm{Q}_{\mathrm{Aux}}$ are shown in Figure 10c. The $\mathrm{Q}_{\mathrm{C} / \mathrm{R}}$ is calculated by the first equation which involves the heat transfer area $\left(A_{C / R}\right)$, total heat transfer coefficient $\left(K_{\mathrm{C} / \mathrm{R}}\right)$, and the temperature difference between condenser of HPC and reboiler of LPC $\left(\Delta t_{C / R}\right)$. According to the steady-state simulation result, the $A_{C / R}$ calculated is $11.803 \mathrm{~m}^{2}$ and the $\Delta t_{C / R}$ is $49.48{ }^{\circ} \mathrm{C}$. The total $K_{\mathrm{C} / \mathrm{R}}$ is assumed as $0.0020448 \mathrm{GJ} /\left(\mathrm{h} \mathrm{m}^{2} \mathrm{~K}\right)$. The $\mathrm{Q}_{\mathrm{C} 2}$ and $\mathrm{Q}_{\mathrm{R} 1}$ are 331.283 and $371.154 \mathrm{~kW}$, respectively. Therefore, the $Q_{\text {Aux }}$ calculated by another equation is $39.871 \mathrm{~kW}$.

The dynamic performance of control structure CS1 for the partial HIPSD process was tested by introducing the feed flowrate and composition disturbances with different degrees at $t=2 \mathrm{~h}$. Figure 11 displays the response of this basic control structure to $5 \%, 10 \%$, and $20 \%$ step changes at the specified value of the FC controller. The black, green, and red solid lines are shown the positive disturbances, while the corresponding dashed lines show the negative disturbances. From the stability of the temperatures on two sensitive trays, when the different degrees of disturbances are introduced in this system, the temperatures can be brought back to the set values by adjusting $Q_{A u x}$ and $Q_{R 2}$ in about $2 \mathrm{~h}$. From the view of the transient deviation, the larger the disturbance in the system, the larger the transient deviation in the product purities. When the disturbances are not more than $10 \%$, the two product purities return close to their set value in about $2 \mathrm{~h}$. However, the purity of benzene in the HPC (B2) is away from the desired purity when the system encounters $+20 \%$ feed flowrate disturbance ( $99.2 \mathrm{~mol} \%$ for the new steady state) and the $-20 \%$ composition disturbance $(97.2 \mathrm{~mol} \%$ for the new steady state).
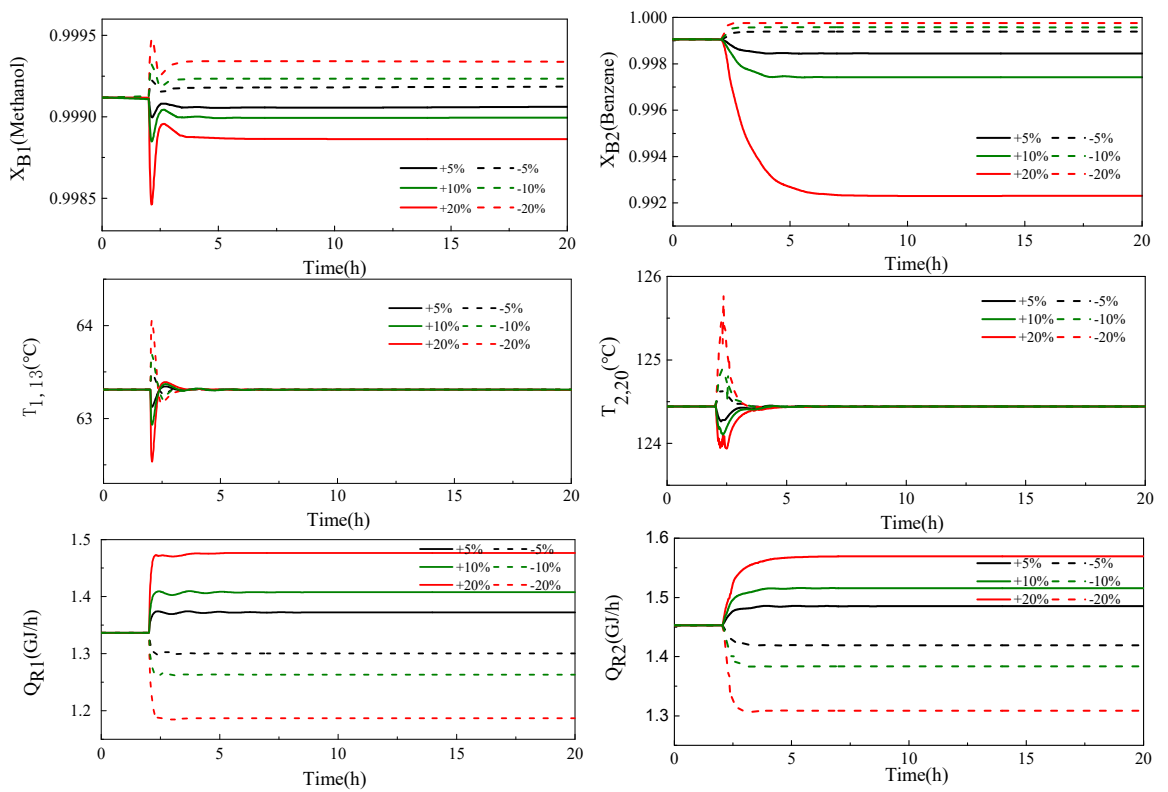

(a) $\pm 5 \%, \pm 10 \%$, and $\pm 20 \%$ feed flowrate disturbances.

Figure 11. Cont. 

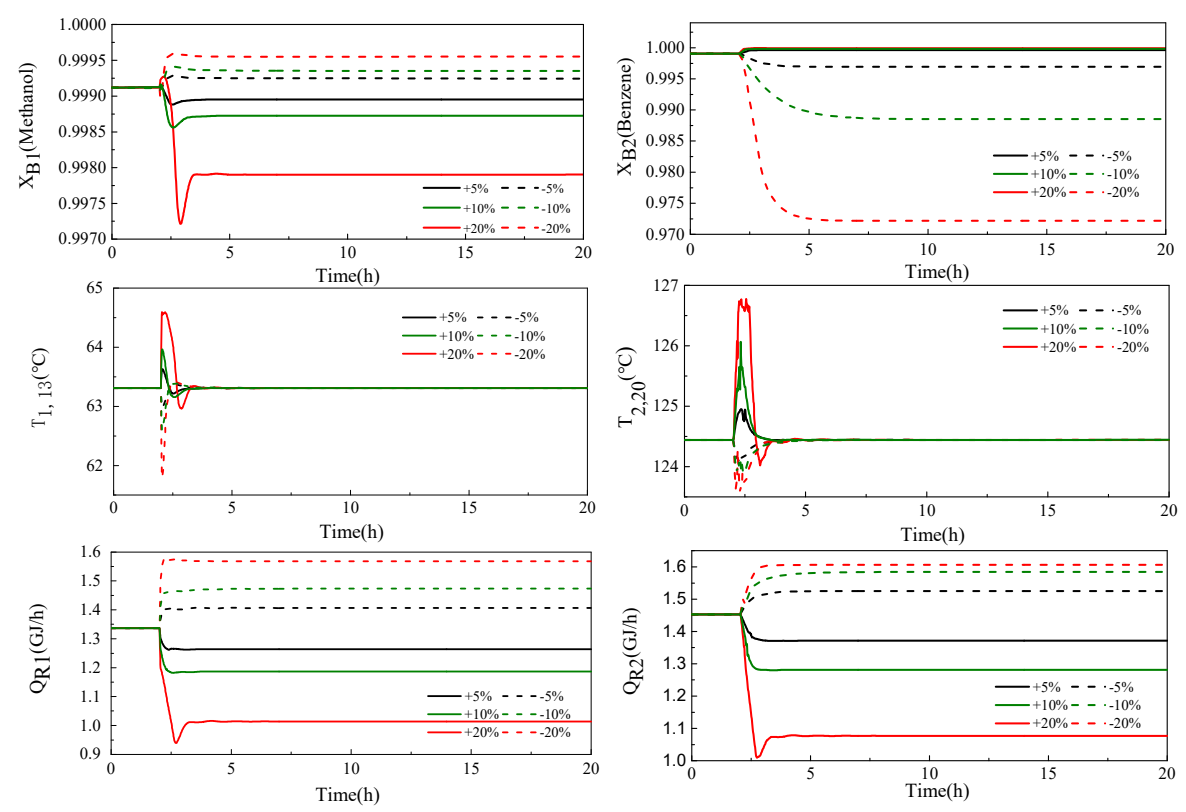

(b) $\pm 5 \%, \pm 10 \%$, and $\pm 20 \%$ feed composition disturbances.

Figure 11. The dynamic responses of the basic control structure.

The results illustrate that the selection of the temperature sensitive plate in the HPC is reasonable. However, the benzene purity cannot turn back to the specified purity, which is mainly because the pressure of the HPC is not fixed as the operating condition. An improved control structure should be developed to overcome this problem.

\subsubsection{Control Structure CS2}

As shown in Figure 11, a large transient deviation appeared in the benzene product purity and a long time is needed to restore a new steady state when this system faces a great disturbance. The pressure-compensated temperature control structure, which has been described in detail and confirmed in some literature $[1,17,25]$, are applied to improve this problem according to the previous control scheme.

The first step to build this control scheme is to compute the VLE data of the liquid mixture on stage 20 according to the steady-state results. Equation (5), which is obtained by the bubble point temperature-pressure diagram (its slope is 5.94765), is used for calculating the corresponding pressure-compensated temperature $T_{P C}$, where the temperature $T$ is for the temperature on stage 20 in the HPC, the pressure $P$ is for the pressure in the top of the HPC. To implement this control scheme in Aspen Dynamic, the third equation in the "flowsheet equation" is used, which is shown in Figure 12. The $\mathrm{T}_{\mathrm{PC}}$ calculated is the input signal of the deadtime block "dead2" and then is fed to TC2. The improved control structure is shown in Figure 12.

$$
T_{P C}=T-(P-6) \times 5.94765 .
$$

The effectiveness of this improved control structure is estimated in Figure 13 for three different degrees of disturbance in feed flowrate and composition. It is noteworthy that the degree of the disturbance and time introduced are the same as the previous control scheme. From Figure 13a, the pressure in the HPC are floated in the range of 5-7 bar when this system faces 5\%, 10\%, and $20 \%$ disturbances. The largest deviation of purity in the bottom stream of HPC reduces to $-0.0005 \mathrm{wt} \%$ and $0.0005 \mathrm{wt} \%$ instead of $-0.007 \mathrm{wt} \%$ and $0.0008 \mathrm{wt} \%$ after $20 \%$ and $-20 \%$ variance in the feed flowrate. The improvement in the methanol product purity is not obvious when the six kinds of disturbance take place in the time equal to $2 \mathrm{~h}$. 


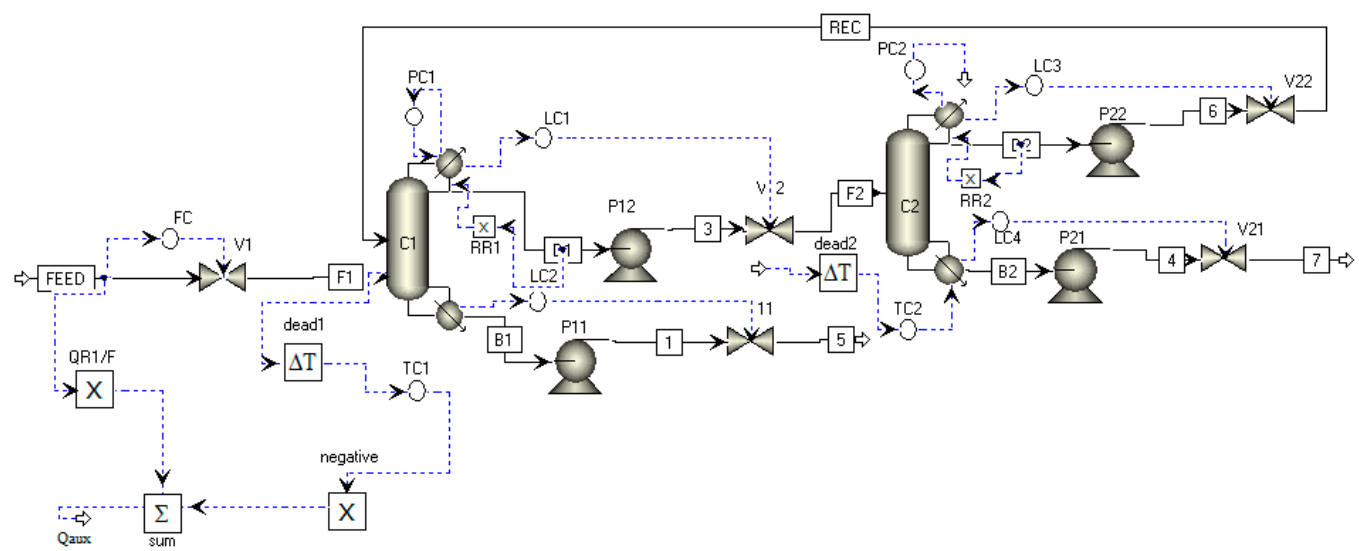

(a) Control structure CS2

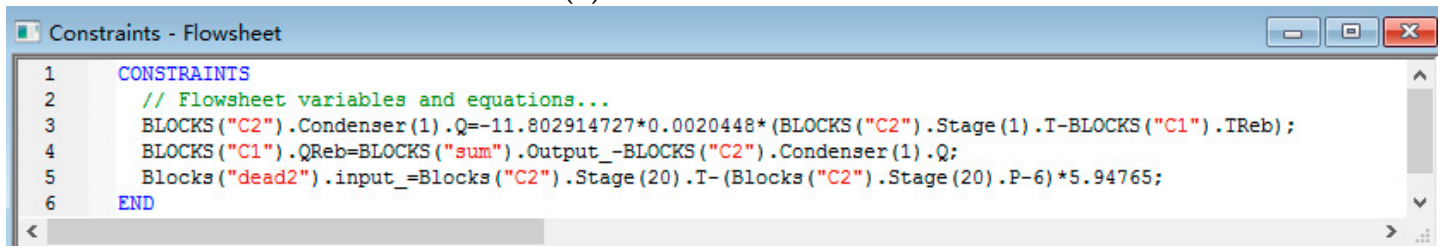

(b) Flowsheet equations

Figure 12. Control structure CS2 and flowsheet equations.
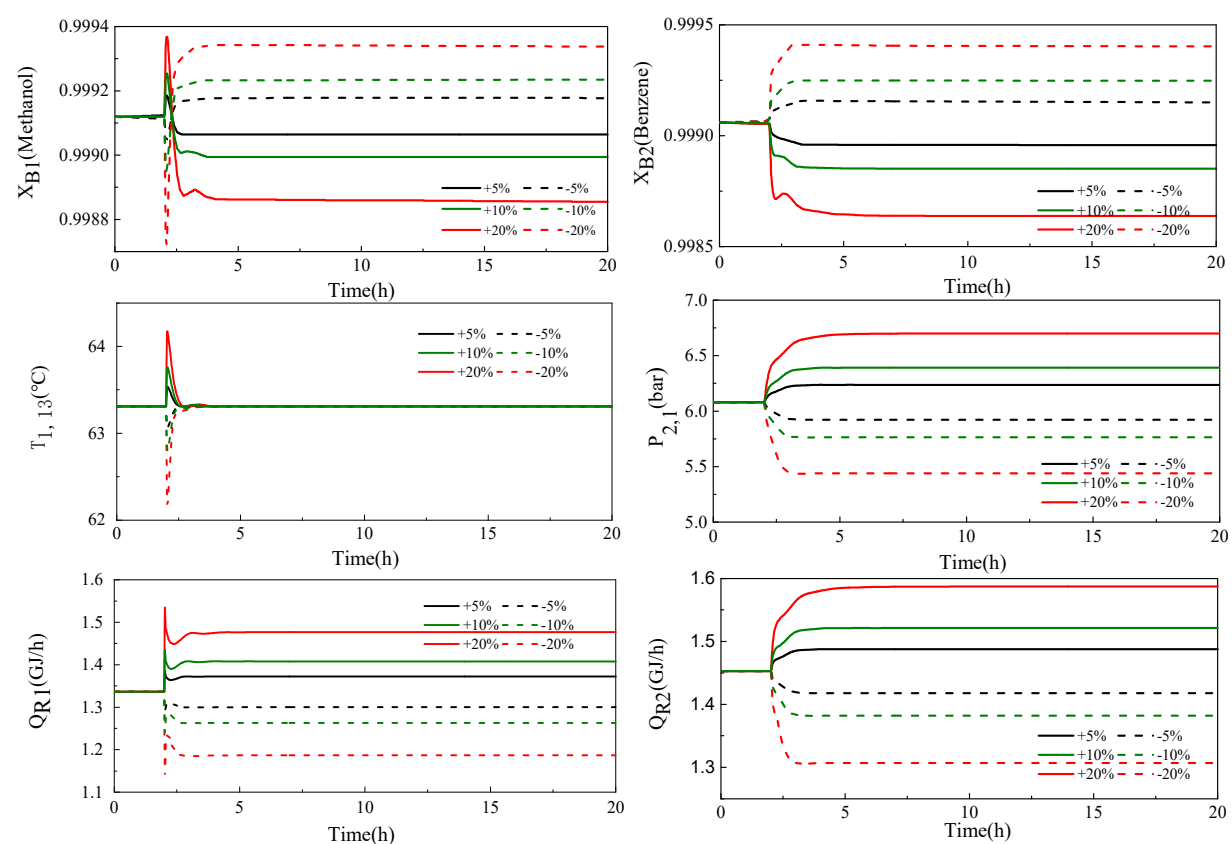

(a) $\pm 5 \%, \pm 10 \%$, and $\pm 20 \%$ feed flowrate disturbance.

Figure 13. Cont. 

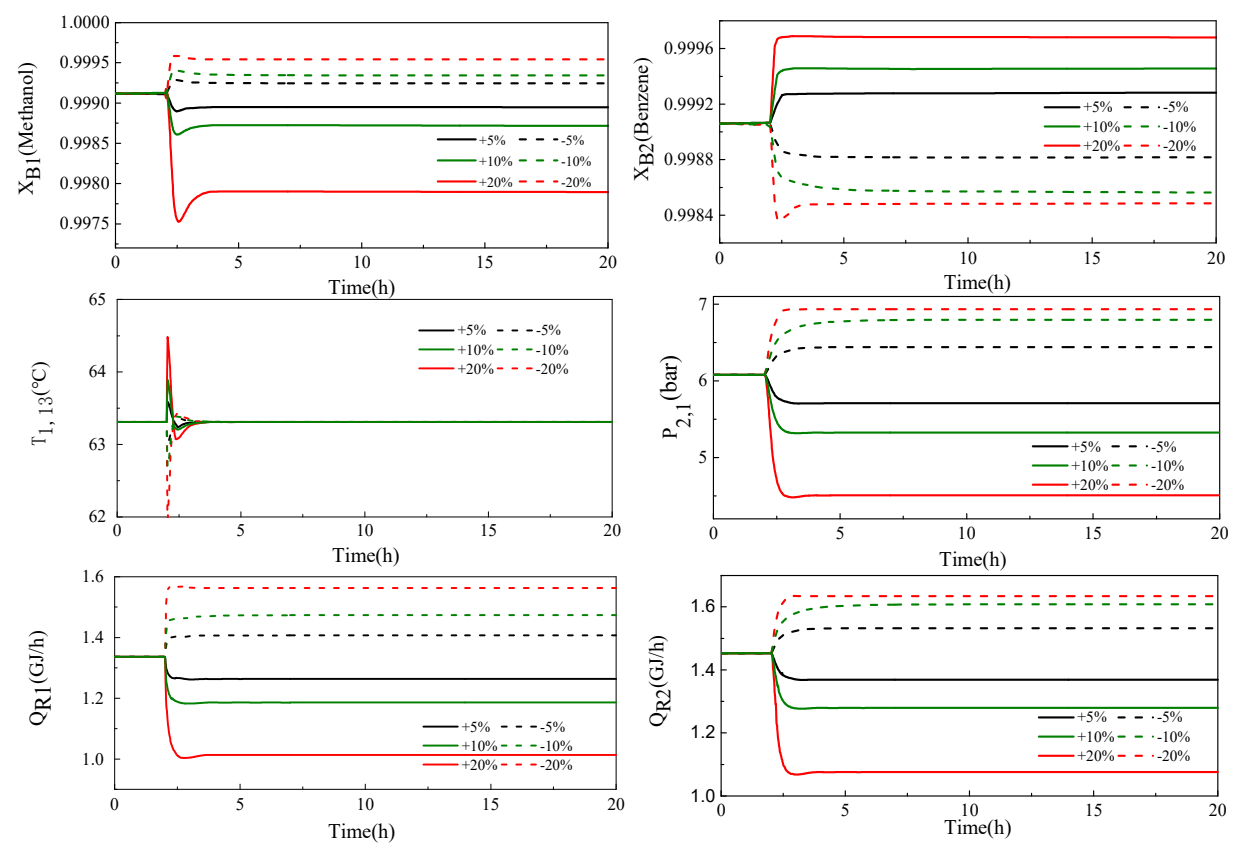

(b) $\pm 5 \%, \pm 10 \%$, and $\pm 20 \%$ feed composition disturbance.

Figure 13. The dynamic responses of control structure CS2.

Figure $13 \mathrm{~b}$ demonstrates the responses for $5 \%, 10 \%$, and $20 \%$ composition disturbances. As can be seen in this figure, the pressure in the HPC is also not fixed, but it changes with the disturbances. From the benzene purity in the bottom stream B2, the purity of benzene shows the value of $99.97 \mathrm{wt} \%$ and $99.83 \mathrm{wt} \%$ for $20 \%$ and $-20 \%$ disturbances in the composition. Compared with basic control structure, the transient deviation decreases from 2.8 to $0.17 \mathrm{wt} \%$. However, the methanol purity in the six cases is similar to those found in the previous control structure.

These results illustrate that the pressure-compensated temperature control structure has a significant improvement in the transient deviation in the $\mathrm{x}_{\mathrm{B} 2}$ (benzene), but the effect in improving the purity of methanol is not obvious when the same disturbances occur at $2 \mathrm{~h}$.

\subsubsection{Control Structure CS3}

The purities of the methanol and benzene cannot be driven to the initial setpoint when the system encounters the disturbances with different degrees in the feed flowrate and composition even though the control structure CS2 can obtain a robust control. A composition/temperature cascade control structure, which integrates the advantages of both composition control and temperature control, was put forward to improve the control structure.

To set up the composition/temperature control structure, two composition controllers (CC1 and CC2) with 3 min deadtime, which detect the content of methanol and benzene in the product streams $\mathrm{B}_{1}$ and $\mathrm{B}_{2}$, were inserted in the loops of TC1 and TC2. In the composition/temperature cascade loop, the composition and temperature controllers are the major and assistant controllers, respectively. It is interesting to note that the operating variables of the temperature controllers are the same as the previous control structure, but the input signal which is the output signal of the composition controller is not a constant. The tuning parameters of the major controllers CC1 and CC2 need to be determined by using the Tyreus-Luyben tuning rules and rerunning the relay-feedback tests. The ultimate gain and period of for CC1 are 14.96 and $25.08 \mathrm{~min}$, and for CC2 are 15.40 and $18.48 \mathrm{~min}$. Figure 14 shows control structure CS3 and control-panels. 


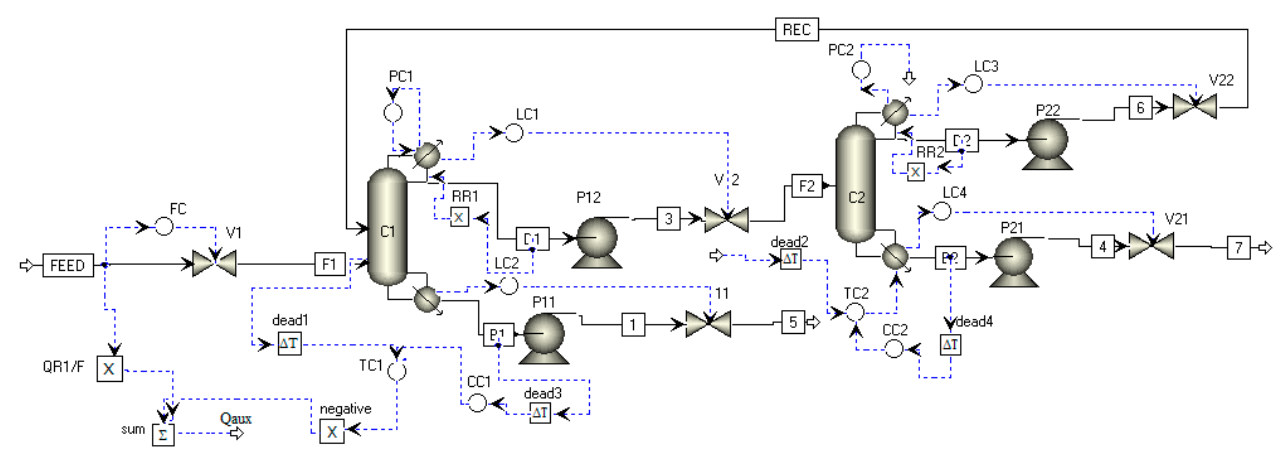

(a) Control structure CS3

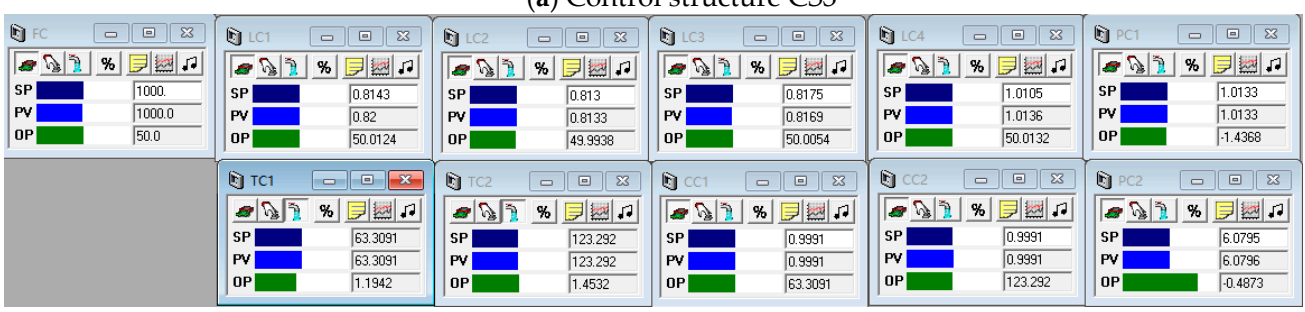

(b) Control-panel

Figure 14. Control structure CS3 and control-panel.

Figure 15 displays the dynamic responses of the control structure encountering the different degrees of disturbance. The solid lines with black, green, and red colors signify the feed flowrate and the methanol composition increases of $5 \%, 10 \%$, and $20 \%$, and the corresponding dashed lines signify the feed flowrate and the methanol composition decreases of 5\%,10\%, and 20\% in Figure 15a,b. As can be seen from Figure 15, the temperatures on the two sensitive plates are not maintained at the initial temperatures of 63.31 and $123.29^{\circ} \mathrm{C}$, but change with the different degrees of disturbance. The larger the variation in the flowrate or composition, the larger the deviation in the initial value. The purities of two products have small transient deviation and can be brought back to the setting point when this control structure faces the $\pm 5 \%, \pm 10 \%$, and $\pm 20 \%$ disturbances in the feed flowrate and composition. The results illustrate that the control structure CS3 can provide a good dynamic control performance.
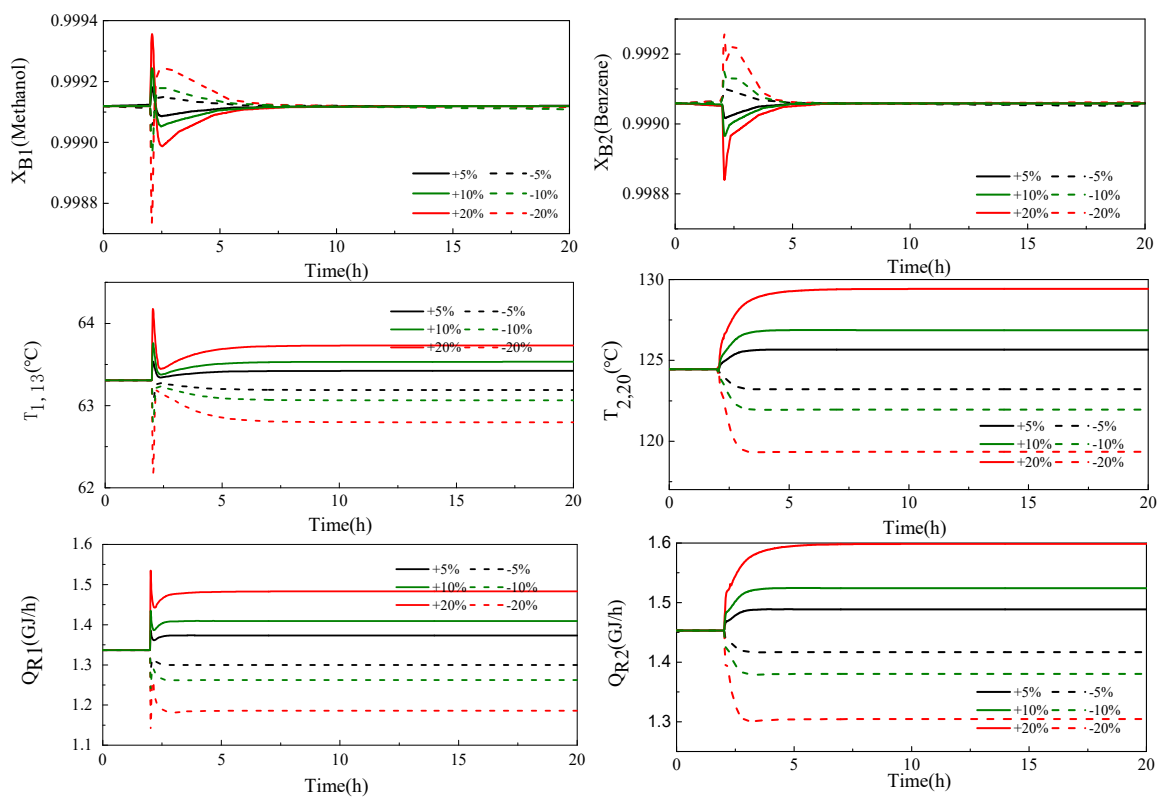

(a) $\pm 5 \%, \pm 10 \%$, and $\pm 20 \%$ feed flowrate disturbance.

Figure 15. Cont. 

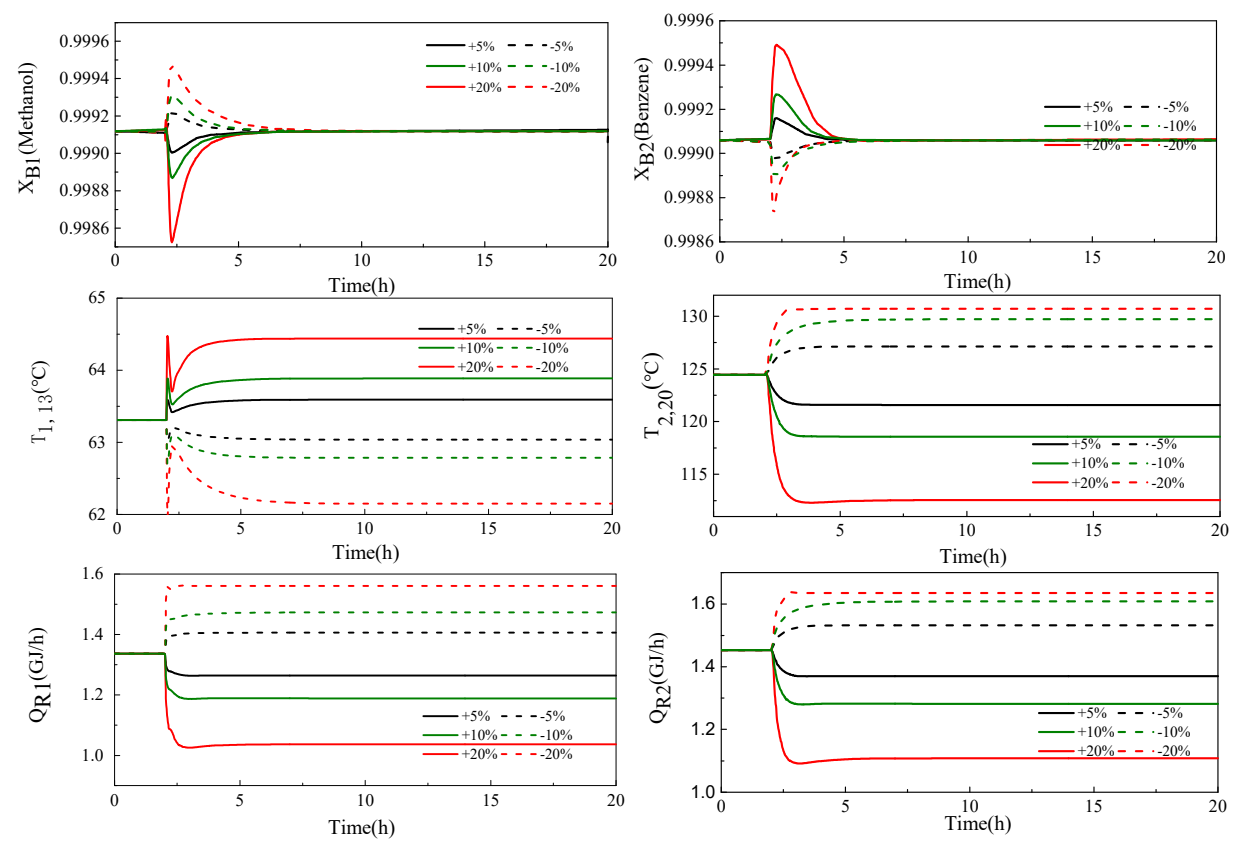

(b) $\pm 5 \%, \pm 10 \%$, and $\pm 20 \%$ feed composition disturbance.

Figure 15. The dynamic responses of composition/temperature cascade control structure.

\subsection{Control Strategies of Fully HIPSD Process}

\subsubsection{Control Structure CS1}

As mentioned earlier, the fully HIPSD process for the separation of the benzene and methanol system has significant economic superiority. Therefore, the dynamic performance of this process was also explored by the Aspen Dynamic. According to the temperature slope and composition slope criterions, the stages 13 and 20 in the LPC and HPC were chosen as the TCS. Figure 16 demonstrates the first control structure, control-panel, and flowsheet equations for the fully HIPSD process. From Figure 16a, the kind and number of the controller are similar to the partial HIPSD process. All of the controllers are proportional control, and the flowrate controller is set as the conventional tuning parameters with $\tau_{\mathrm{I}}$ of $0.3 \mathrm{~min}$ and $\mathrm{K}_{\mathrm{C}}$ of 0.5 . Four level controllers have the $\tau_{\mathrm{I}}$ of $9999 \mathrm{~min}$ and $\mathrm{K}_{\mathrm{C}}$ of 2. Note that the temperature $T_{13 \text { th }}$ is controlled by changing RR1. The corresponding $\tau_{I}$ and $K_{C}$ are calculated by running the relay-feedback rules. The gain and integral time of TC1 and TC2 are 9.97 and $3.39 \mathrm{~min}, 17.16$ and $5.28 \mathrm{~min}$, respectively.

The top of the HPC and bottom of the LPC share only one heat exchanger, the heat duty of the heat exchanger is equal to the product of $\mathrm{K}_{\mathrm{C} / \mathrm{R}}$ (assumption for $0.0020448 \mathrm{GJ} /\left(\mathrm{h} \mathrm{m}^{2} \mathrm{~K}\right)$ ), $\mathrm{A}_{\mathrm{C} / \mathrm{R}}$, and $\Delta t_{\mathrm{C} / \mathrm{R}}$. The "flowsheet equation" function in the Aspen dynamic aids in implementing the fully heat integration. The $Q_{R 1}$ and $Q_{C 2}$ are respectively calculated by the first and second equations. The performance of the control structure will be estimated in the next paragraph. 


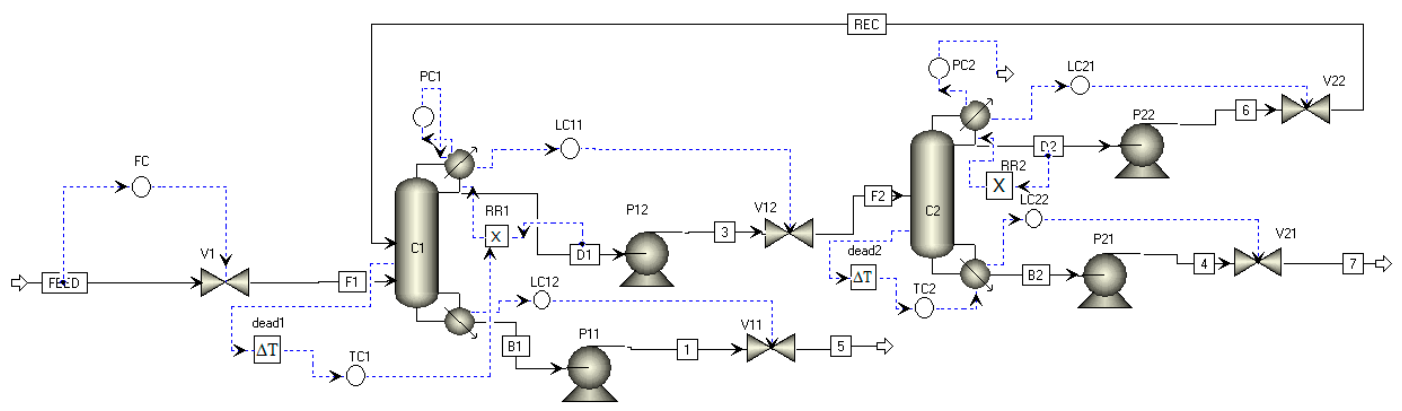

(a) Basic control structure

\begin{tabular}{|c|c|c|c|c|c|c|c|c|c|}
\hline $\mathrm{OPFC}$ & $\square$ 回 83 & (1) $\mathrm{PC1}$ & 口 $1 \Sigma^{2}$ & (iv) LC11 & $\square \quad 03$ & (i) $L C 21$ & $\square$ 回 & (i) $\mathrm{TC1}$ & $\square \quad \square$ \\
\hline ats & $\%$ 圈国品 & $\theta_{0}^{2}$ & $\%$ 圈国公 & n. & 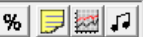 & a & $\%$ 圈国罗 & 5 & 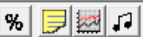 \\
\hline SPI & 999.9998 & $\mathrm{SP}$ & 1.0133 & SP & 0.7942 & SP & 0.8266 & SP & 63.5402 \\
\hline PV & 999.9998 & Pv & 1.0133 & $\mathrm{PV}$ & 0.7942 & PV & 0.8265 & $\mathrm{PV}$ & 63.5402 \\
\hline OP & 50.0001 & OP & -1.3335 & $\mathrm{OP}$ & 49.9916 & OP & 49.9766 & OP & 0.6008 \\
\hline & & (i) $P C 2$ & \begin{tabular}{|l|l}
$\square$ & 0 \\
\end{tabular} & (i) LC12 & $\square \quad 083$ & (10) LC22 & \begin{tabular}{|lll}
0 & 03 \\
\end{tabular} & (i) TC2 & \begin{tabular}{|lll}
0 & $\square$ \\
& & 0
\end{tabular} \\
\hline & & - $\sqrt{2} ?$ & $\%$ 荨国品 & 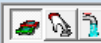 & 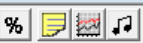 & ถั) & $\%$ 目国 布 & $\theta$ & $\%$ 目国 \\
\hline & & SPI & 6.0818 & SPI & $\widehat{0.7997}$ & SPI & $\sqrt{1.0206}$ & SP & 124.8581 \\
\hline & & PV & 6.0818 & $\mathrm{PV}$ & 0.7997 & $\mathrm{PV}$ & 1.0212 & $\mathrm{PV}$ & 124.8581 \\
\hline & & OP & -1.238 & OP & 50.0021 & $\mathrm{OP}$ & 50.0838 & $\mathrm{OP}$ & 1.493 \\
\hline
\end{tabular}

(b) control panel

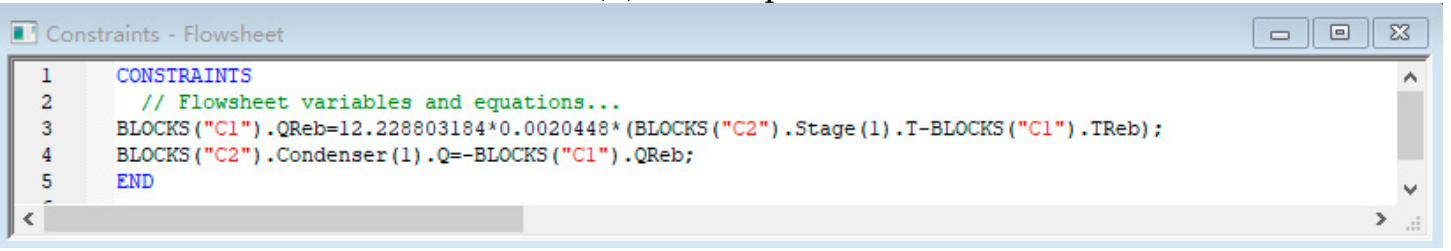

(c) flowsheet equations

Figure 16. Basic control structure, control-panel, and flowsheet equations for the fully HIPSD process.

The disturbances with different degrees were utilized to test the control performance for the fully HIPSD process. Figure 17 a gives the dynamic responses when 5\%, 10\%, 20\% step change in the feed flowrate occur at the time equal to $2 \mathrm{~h}$. The temperatures on two TCS are maintained to the set point (63.5 and $124.8^{\circ} \mathrm{C}$ ) in approximately $2 \mathrm{~h}$ after the flowrate disturbances occurred at $2 \mathrm{~h}$. This is caused by the controllers "TC1" and "TC2" that can readjust the RR1 and $\mathrm{Q}_{\mathrm{R} 2}$ for achieving a new steady-state condition. The product purities of five cases $( \pm 5 \%, \pm 10 \%$, and $-20 \%$ flowrate disturbances) are held quite close to the specified purity, but the transient deviation in the purity of benzene is $0.9 \mathrm{wt} \%$ when the flowrate changes from 1000 to $1200 \mathrm{~kg} / \mathrm{h}$. The main culprit is that the increase of the feed flowrate leads to a sharp increase in the pressure of HPC and results in the concentration of methanol on the sensitive stage, but the temperature on stage 20 is controlled at a constant.

Figure $17 \mathrm{~b}$ illustrates the dynamic responses of the control structure for the feed composition disturbance with three different degrees. The solid and dashed lines are for positive and negative change, respectively. The black, green, and red lines demonstrate the 3\%, 5\%, and $10 \%$ step change in the feed composition. The results of the response for the six cases are similar to the six cases in Figure 17a. The larger the variance in the composition, the larger the deviation in the benzene purity. The deviation $(0.8 \mathrm{wt} \%)$ occurred when the methanol concentration decreases from 70 to $63 \mathrm{wt} \%$.

When the methanol concentration changes more than $7 \%$, the flowrate of the recycling stream increases to the point which caused the liquid level of the reflux tank in the LPC to exceed $100 \%$ and the system was forced to shut down. This is caused by more benzene in the feed stream making the product in the bottom of HPC increase and the pressure rise rapidly.

These results illustrate that the selection of the temperature sensitive plate is suitable, and this control structure can implement the robust control. However, it cannot maintain the purity of the 
product at the specification after encountering a large disturbance in the composition. Therefore, it is necessarily to develop several improved structures to overcome this problem.
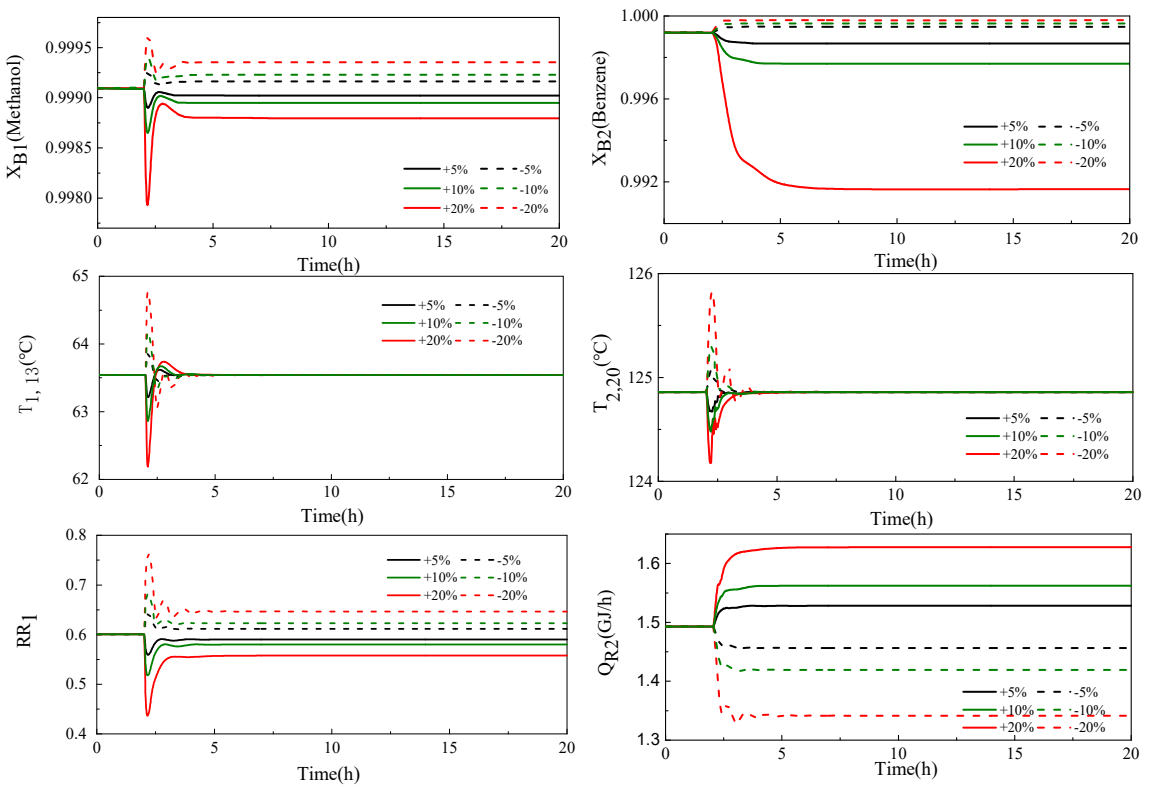

(a) $\pm 5 \%, \pm 10 \%$, and $\pm 20 \%$ feed flowrate disturbance.
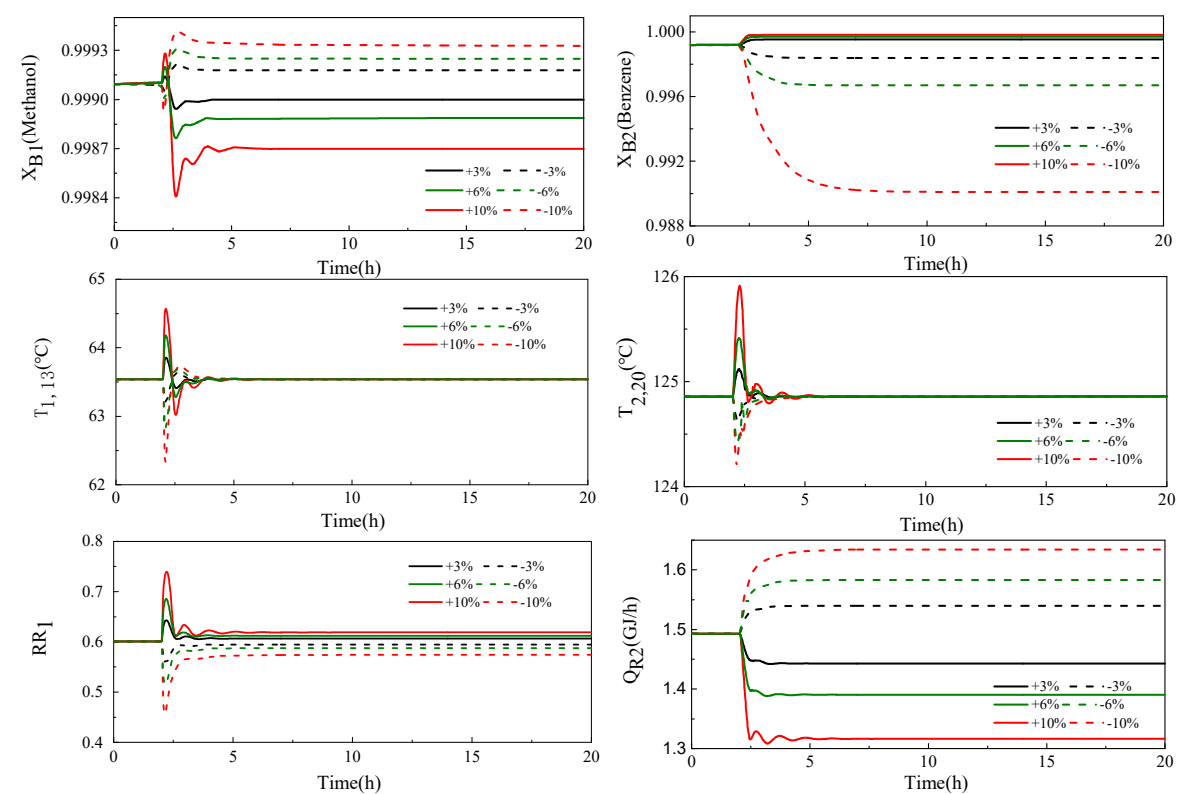

(b) $\pm 5 \%, \pm 6 \%$, and $\pm 10 \%$ feed composition disturbance.

Figure 17. The dynamic responses of the basic control structure.

\subsubsection{Control Structure CS2}

As described above, the high purity benzene product cannot be obtained when the large disturbance is introduced in the previous control structure. The pressure-compensated temperature can improve the problem that the changing pressure with operating condition results in the large transient deviation in the benzene product in the HPC.

The VLE data also needs to be recalculated before establishing the new control structure. The major reason is that the operating parameters for the fully HIPSD process are different from that for the partial HIPSD process which will result in the difference in the composition on stage 20 in the HPC. Equation (6) shows the relationship of the temperature on stage 20 in the HPC, the pressure in the top 
of the HPC, and the pressure-compensated temperature $T_{P C}$. In Aspen Dynamic, $T_{P C}$ can be calculated by the third equation in the "flowsheet equation" function. As shown in Figure 18, the input signal of the "dead 2" block is the $T_{P C}$. Note that the output signal of the temperature controller TC2, which is the ratio of reboiler heat duty $1.49297 \mathrm{GJ} / \mathrm{h}$ to the flowrate $1000 \mathrm{~kg} / \mathrm{h}$, is 0.0015 and not connected the reboiler, but the multiplier block. The effectiveness of this improved structure will be illustrated in the next section.

$$
T_{P C}=T-(P-6) \times 7.5722 .
$$

The disturbances in the flowrate and composition with several different degrees were used to test the dynamic performance. The obtained results are demonstrated in Figure 19. Figure 19a shows the response of the flowrate with $5 \%, 10 \%$, and $20 \%$ step change, and Figure $19 \mathrm{~b}$ shows the response of the methanol component with $3 \%, 6 \%$, and $10 \%$ step change.

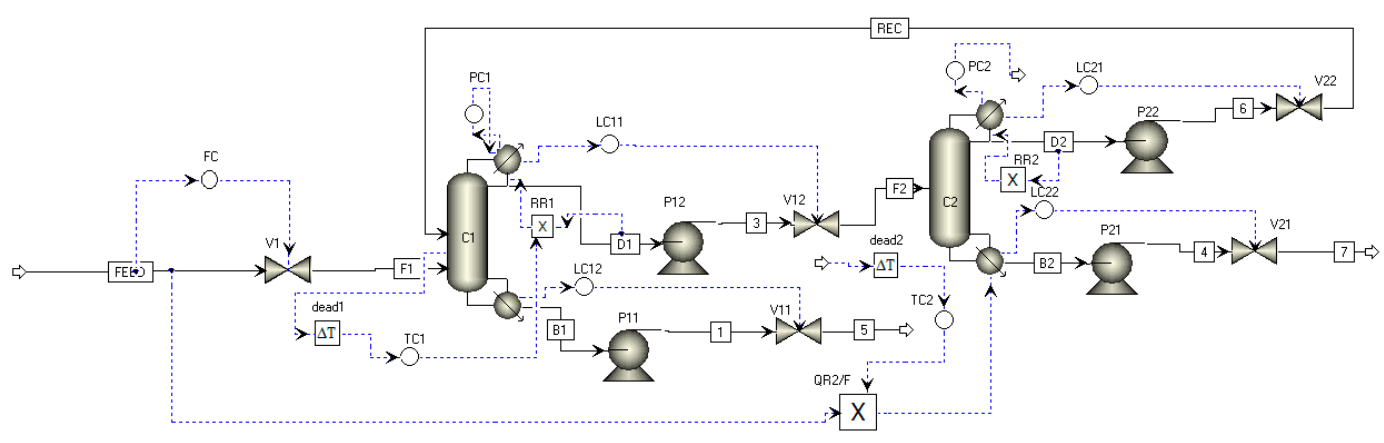

(a) Pressure-compensated temperature control structure

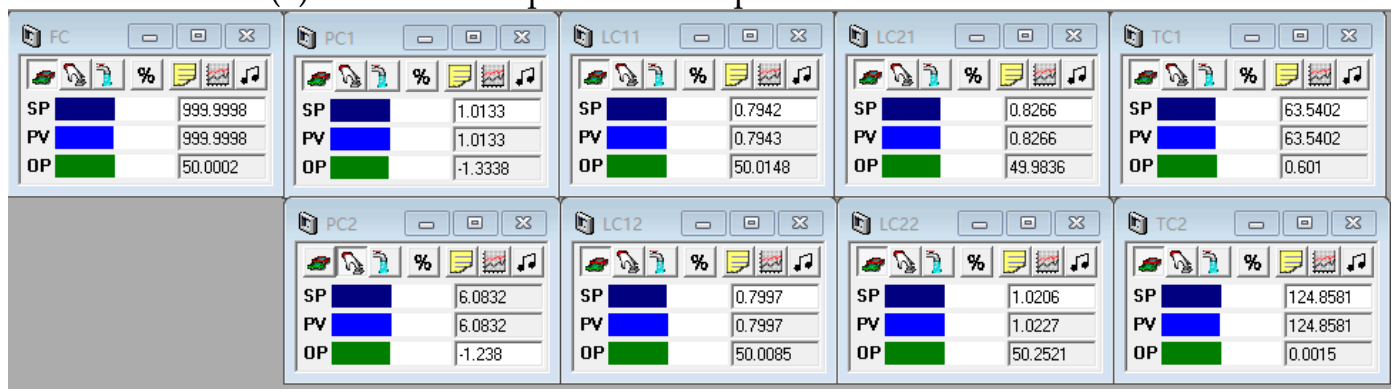

(b) control panel

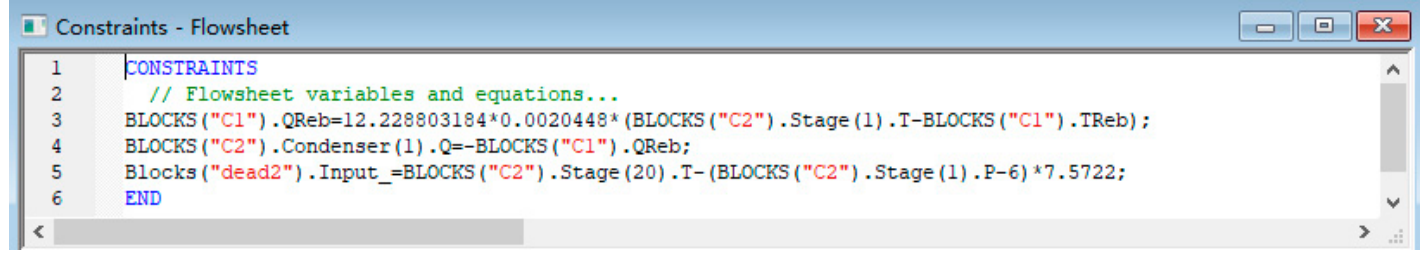

(c) Flowsheet equations

Figure 18. Pressure-compensated temperature control structure of flowsheet, control panel, and flowsheet equations. 

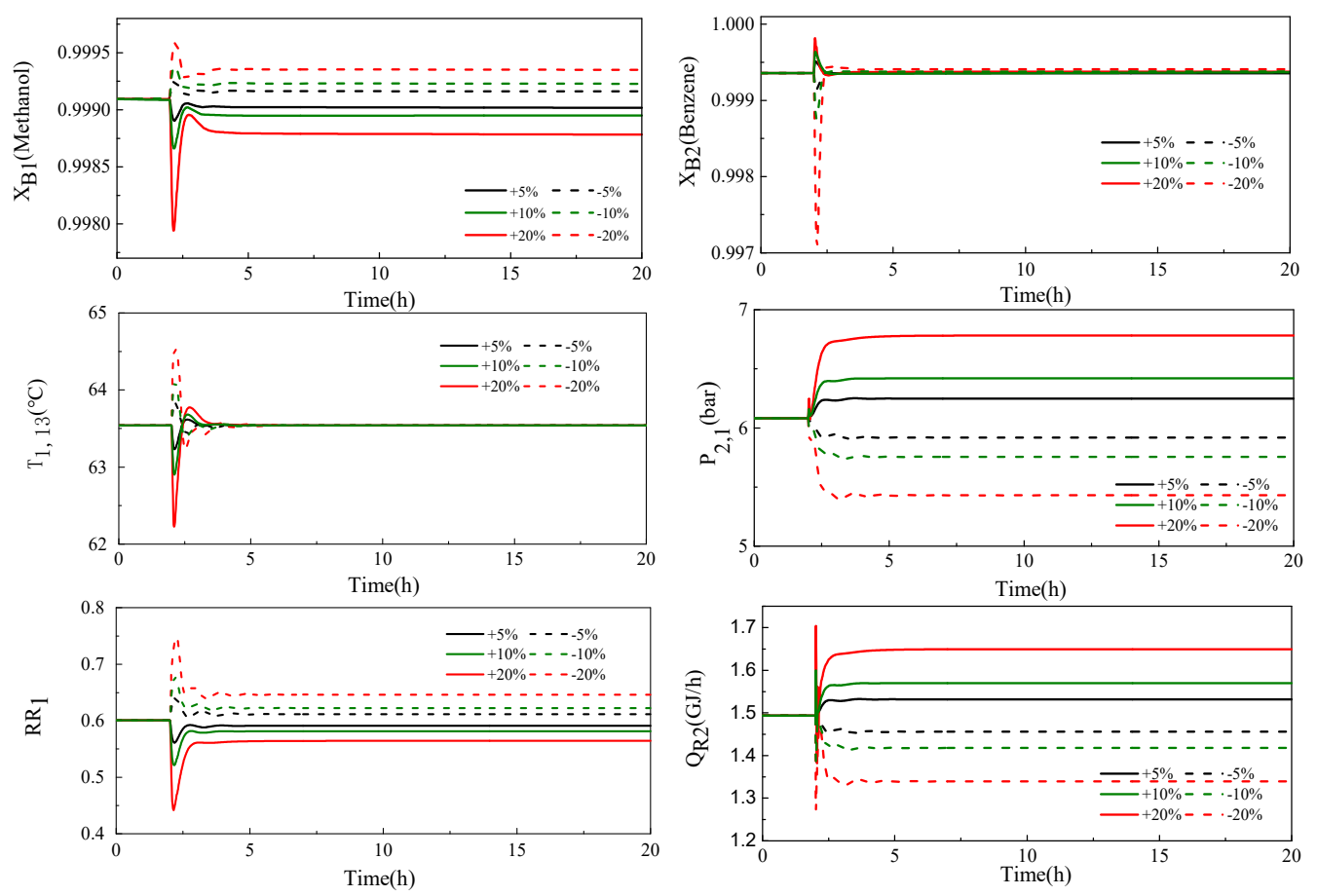

(a) $\pm 5 \%, \pm 10 \%$, and $\pm 20 \%$ feed flowrate disturbance.
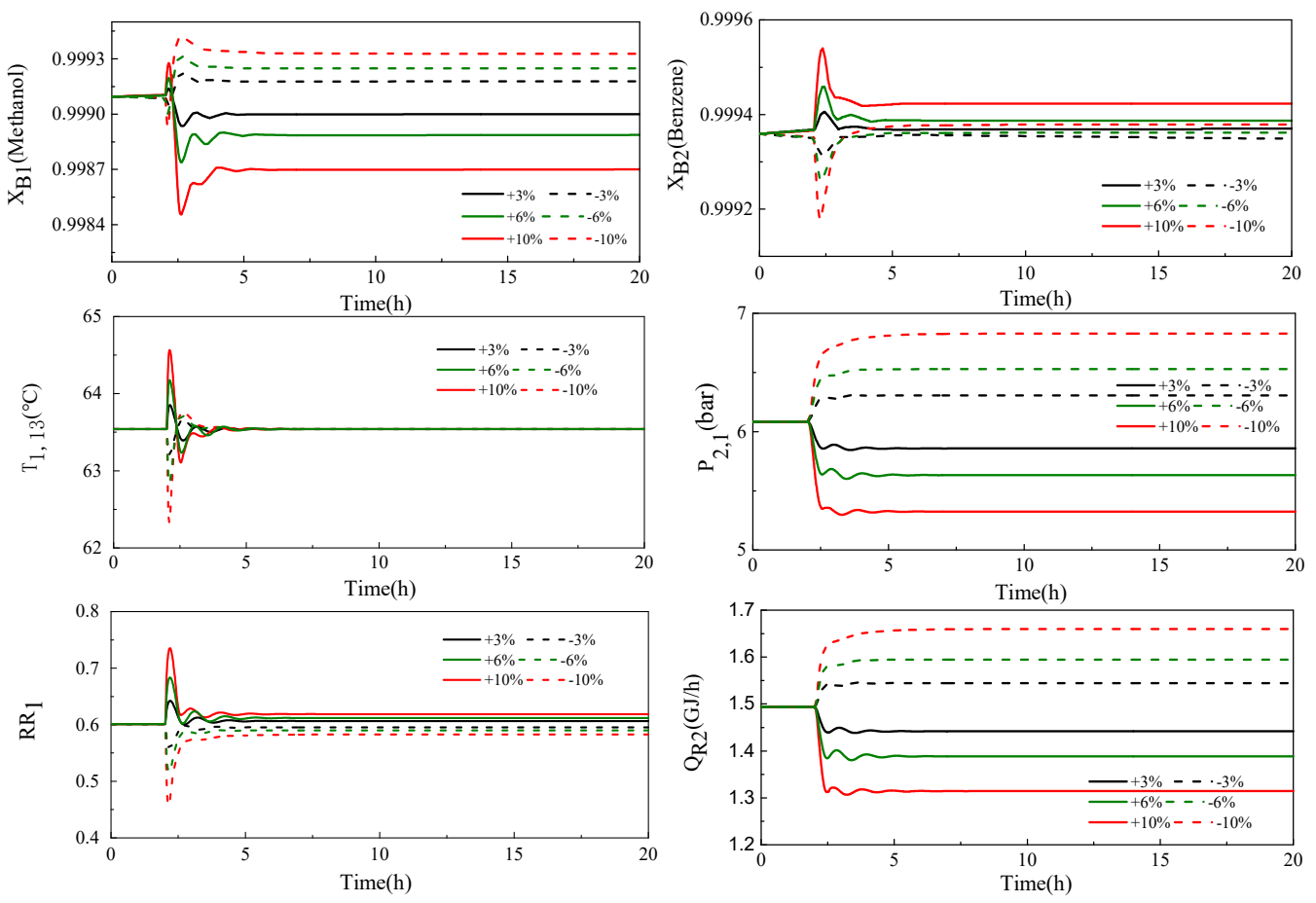

(b) $\pm 5 \%, \pm 6 \%$, and $\pm 10 \%$ feed composition disturbance.

Figure 19. The dynamic responses of pressure-compensated temperature control structure.

From the variation of the pressure in the HPC, the pressure is floating from 5 to 7 bar when the system encounters the 12 kinds of disturbances. From the benzene purity in the bottom stream $\mathrm{B}_{2}$, the product purity can return to the specified value after facing the $5 \%, 10 \%$, and $20 \%$ flowrate disturbances. Meanwhile, the product purity also can be held close to the specification when the methanol composition in the feed is varied $3 \%, 6 \%$, and $10 \%$. The most purity deviation decreases more sharply than control structure CS1. The time to reach a new steady state was reduced from $\sim 3$ to $1 \mathrm{~h}$ after experiencing the same disturbance in the flowrate and composition. However, the methanol 
product purity and the transient deviation in the purity are similar to the response for the control structure CS1.

These results illustrate that the pressure-compensated temperature control structure can improve the purity of the benzene, decrease the transient deviation in the purity and the time to reach a new steady state, but play a small role in the increase of methanol purity.

\subsubsection{Control Structure CS3}

To keep the methanol purity at the set point, the third control structure which is the composition/temperature cascade control structure was set up to implement the aim.

As for Figure 20, the composition controller CC1 with $3 \mathrm{~min}$ is added to the temperature control loop. The purity of the methanol product is detected and input in the CC1 composition controller, and the output signal is the setpoint of the TC1 temperature controller. Note that the setpoint is not fixed, but changes with the disturbances in the flowrate and composition. The CC1 composition controller, which is cascade with TC1, is tuned by running the relay-feedback tests and using the Tyreus-Luyben tuning rules. The corresponding tuning parameters of $\mathrm{CC} 1$ are $\mathrm{K}_{\mathrm{C}}=35.82, \mathrm{t}=31.68 \mathrm{~min}$.

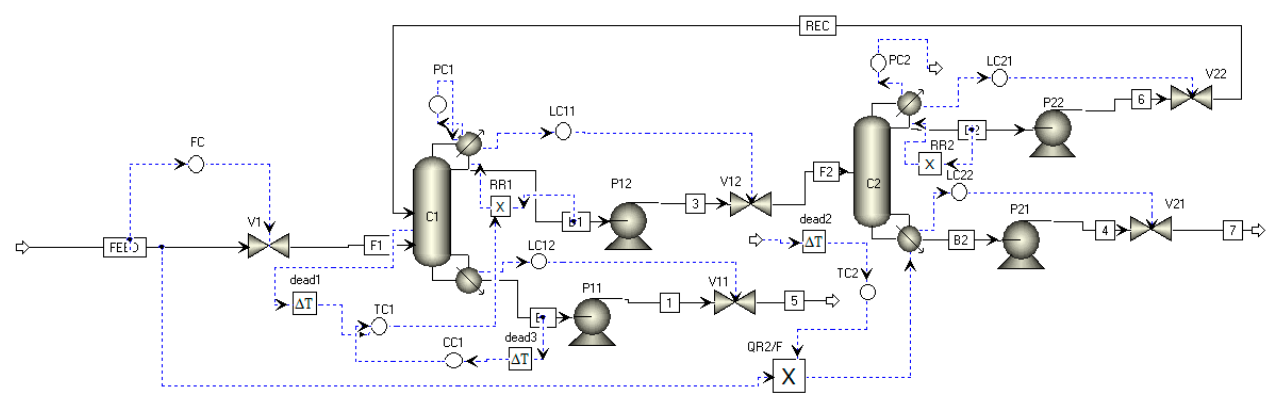

(a) The flowsheet of Control structure CS3

\begin{tabular}{|c|c|c|c|c|c|c|c|c|c|}
\hline (N) $\mathrm{FC}$ & \begin{tabular}{|l|l|}
0 & 03 \\
\end{tabular} & [D] $\mathrm{PCl}$ & 口 183 & [v] LC11 & \begin{tabular}{|l|l|}
0 & 0 \\
\end{tabular} & [N] $L C 21$ & \begin{tabular}{|l|l}
0 & 03 \\
\end{tabular} & [D. TC1 & \begin{tabular}{|l|l|}
0 & 0 \\
\end{tabular} \\
\hline 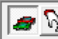 & $\%$ 目国品 & $\theta$ & $\%$ 目盗 & an & $\%$ 国整 & $\mid$ & $\%$ 国整 & $\theta \sqrt{2}$ & $\%$ 国这品 \\
\hline SP I & 999.9998 & SP & 1.0133 & SPI & 0.7942 & SP & 0.8266 & SP & 63.5464 \\
\hline PV & 999.9998 & PV & 1.0132 & PVI & 0.7914 & PV & 0.8262 & PVI & 63.5449 \\
\hline $\mathrm{OP}$ & 50.0001 & OP & -1.3336 & $\mathrm{OP}$ & 49.9974 & OP & 49.9802 & $\mathrm{OP}$ & 0.6009 \\
\hline (i) $\subset \mathrm{CC}$ & \begin{tabular}{|l|l} 
& 回 \\
\end{tabular} & [N] $P C 2$ & \begin{tabular}{|l|l|l|}
0 & 回 & 83 \\
\end{tabular} & {$[\mathrm{~N}]$} & \begin{tabular}{|l|l|}
0 & (1) \\
\end{tabular} & (i) & 回 83 & (D) TC2 & $0 \quad \square \quad 83$ \\
\hline 8 & $\%$ 目国品 & $-\sqrt{2}$ & $\%$ 目恝 & $\Rightarrow$ & $\%$ 目整片 & 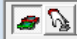 & $\%$ 目国然 & 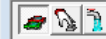 & $\%$ 目瑟 \\
\hline SP & 0.9991 & SP & 6.0824 & SPI & 0.7997 & SP & 1.0206 & SPI & 124.8581 \\
\hline PVI & 0.9991 & PV & 6.0824 & PVI & 0.7996 & PV & 1.0218 & $\mathrm{PV}$ & 124.8577 \\
\hline OP & 63.5464 & $\mathrm{OP}$ & -1.238 & $\mathrm{OP}$ & 50.0174 & OP & 50.1122 & $\mathrm{OP}$ & 0.0015 \\
\hline
\end{tabular}

(b) Control panel

Figure 20. Control structure CS3 of flowsheet and control panel.

In the next part, we will test the dynamic performances by introducing the same disturbances in flowrate and composition at $2 \mathrm{~h}$ to verify the effectiveness of the improved structure.

The responses for the different degree of disturbances are displayed in Figure 21. The different color lines stand for the same variation in the feed flowrate and composition in the basic control structure. From Figure 21, the product purity of methanol can be brought back to the specified value after encountering feed flowrate changes of 50,100 , and $200 \mathrm{~kg} / \mathrm{h}$ and the composition changes of 2.1, 4.2 , and $7 \mathrm{wt} \%$ methanol. The larger the disturbances in the flowrate and composition, the larger the transient deviation in the initial purity. However, the transient deviation is smaller than those in the previous structure control. Meanwhile, the time to reach a new steady state reduces from 4 to $1 \mathrm{~h}$. 

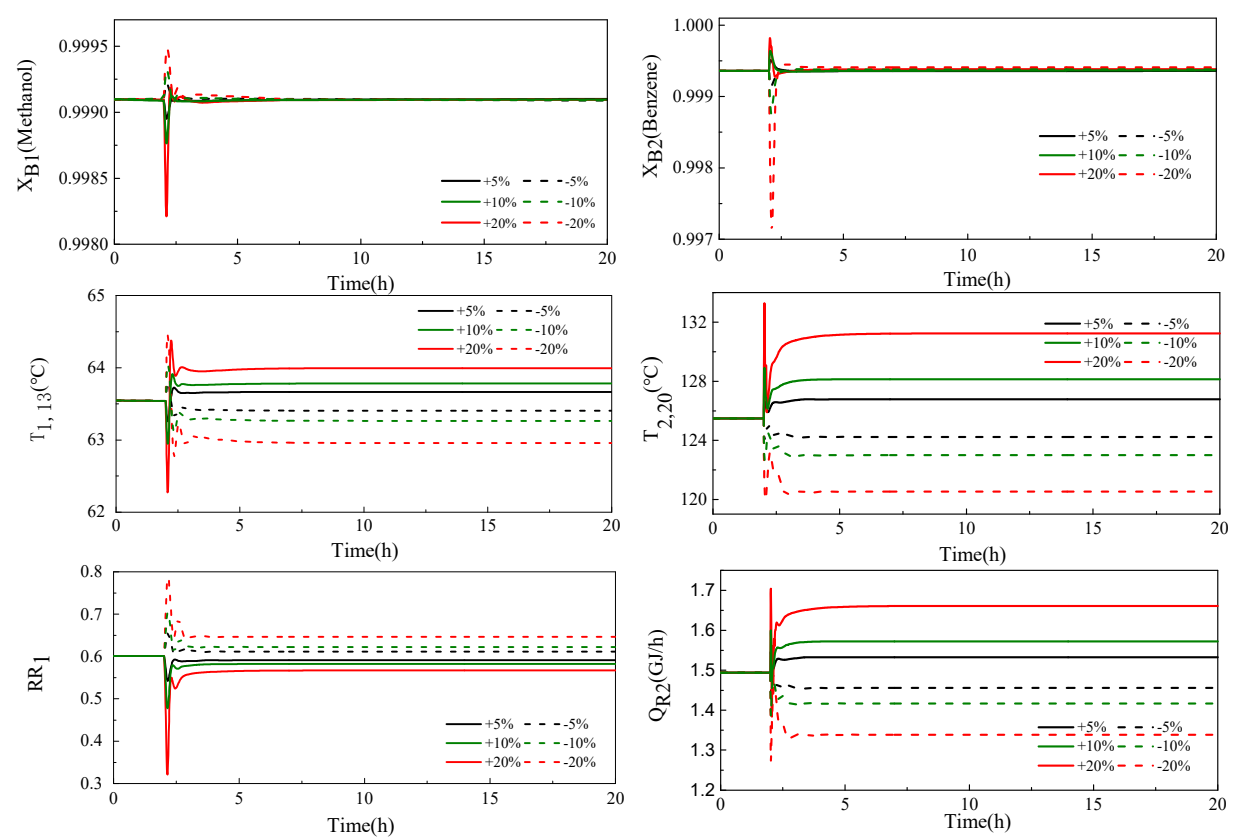

(a) $\pm 5 \%, \pm 10 \%$, and $\pm 20 \%$ feed flowrate disturbance.
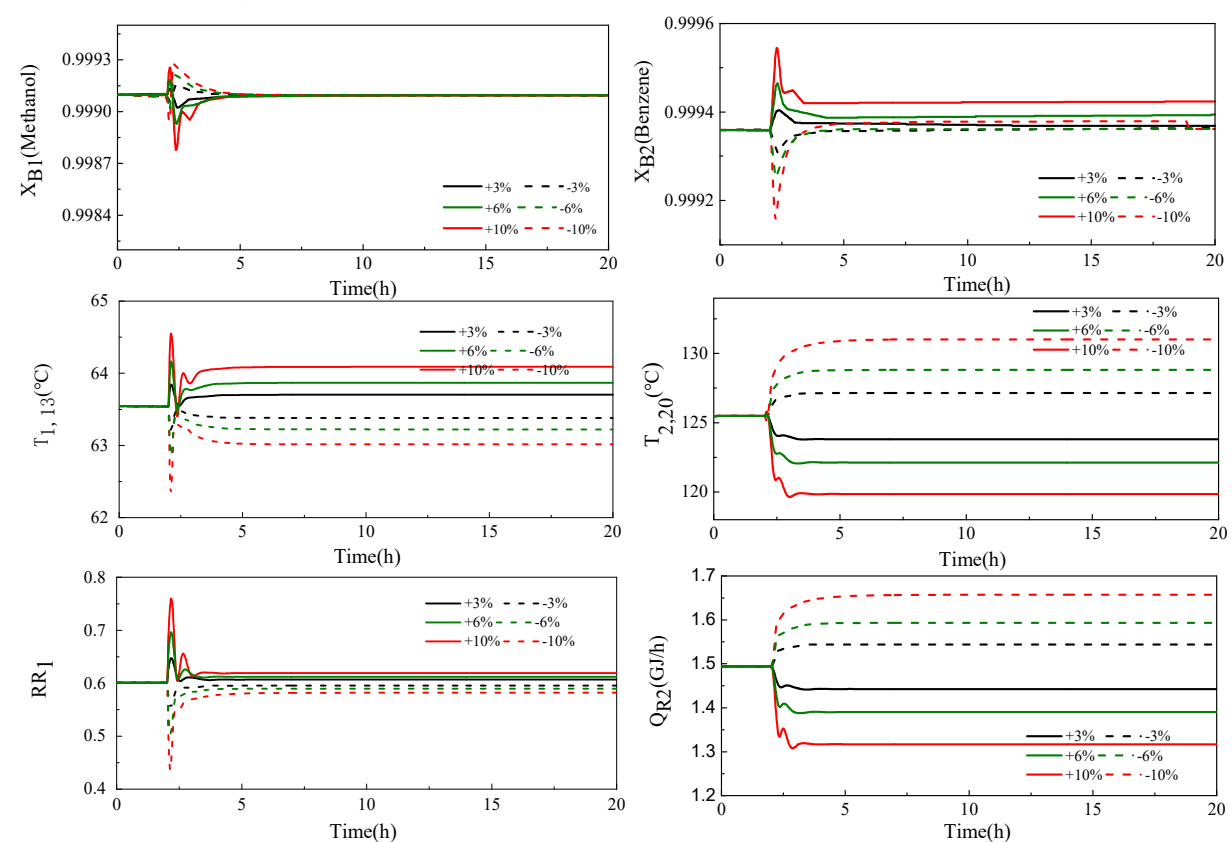

(b) $\pm 5 \%, \pm 6 \%$, and $\pm 10 \%$ feed composition disturbance.

Figure 21. The dynamic responses of control structure CS3.

Compared with previous control structure, the benzene purity is almost unchanged when the system faces the disturbances in the feed flowrate and composition. The methanol purity deviation in the new steady state is maintained within acceptable range when there is a 3\%,6\%, and $10 \%$ step change in the methanol composition. This reveals that the control structure CS3 can provide a good dynamic control performance.

\section{Conclusions}

The PSD with two energy-saving modes for the separation of the benzene/methanol azeotropic system was studied by Aspen Plus and Aspen Dynamics. We contrasted the economy and controllability of the PSD with two heat integration modes. The optimization results show that the fully HIPSD 
process with a TAC of $\$ 187,189$ has some economic benefit compared with the partial HIPSD process with a TAC of $\$ 198,891$.

The temperature profile in the HPC rose rapidly near the bottom of this column and the maximum of temperature slope value occurred in the last stage, which is the bottom of the HPC. The composition slope profile was proposed to assist with the selection of the temperature sensitive plate. According to the two criterions, stages 13 and stage 20 in the LPC and HPC were chosen as the TCS. Several control structures were developed to evaluate the industrial application and check the rationality of the selection of the temperature sensitive plate. The different degrees of disturbances in the feed flowrate and composition were introduced in two processes at $2 \mathrm{~h}$. The results illustrate that the selection of the TCS is reasonable and the composition/temperature control structure can provide rust control performance for the PSD with two heat integrated modes. Compared with the partial HIPSD mode, the fully HIPSD mode can handle much smaller composition disturbance despite little economic benefit.

These works can provide a reference for selecting TCS, especially for azeotropic systems whose maximum value of temperature slope profile occurs in the bottom of the column. Meanwhile, the findings can also help engineers to weigh the economy against controllability for selection of the suitable separating process.

Author Contributions: Conception and design: Z.Z., L.L.; Process simulation and optimization: L.L., Z.Z.; Establishment of control structure: H.L., H.H.; Analysis and interpretation: L.L., H.H.; Data collection: H.L., H.H.; Writing the article: L.L.; Critical revision of the article: L.L., Z.Z., H.L., H.H.; Final approval of the article: L.L., Z.Z., H.L., H.H.

Funding: This research was funded by the project of science and technology research program of Chongqing Education Commission of China (No. KJQN201901429).

Acknowledgments: The authors gratefully acknowledge the anonymous reviewers for the insightful comments and suggestions, which improved the quality of this paper to a large extent. Additionally, the authors also gratefully acknowledge the financial support by the project of science and technology research program of Chongqing Education Commission of China (No. KJQN201901429).

Conflicts of Interest: The authors declare no conflicts of interest.

\section{References}

1. Luyben, W.L. Design and Control of a Fully Heat-Integrated Pressure-Swing Azeotropic Distillation System. Ind. Eng. Chem. Res. 2008, 47, 2681-2695. [CrossRef]

2. Wang, Y.; Zhang, Z.; Zhang, H.; Zhang, Q. Control of Heat Integrated Pressure-Swing-Distillation Process for Separating Azeotropic Mixture of Tetrahydrofuran and Methanol. Ind. Eng. Chem. Res. 2015, 54, 1646-1655. [CrossRef]

3. Zhu, Z.; Wang, L.; Ma, Y.; Wang, W.; Wang, Y. Separating an Azeotropic Mixture of Toluene and Ethanol Via Heat Integration Pressure Swing Distillation. Comput. Chem. Eng. 2015, 76, 137-149. [CrossRef]

4. Lv, L.Z.L.; Liu, H.; Li, H.; Sun, S. Comparison of Continuous Homogenous Azeotropic and Pressure-Swing Distillation for a Minimum Azeotropic System Ethyl Acetate N-Hexane Separation. Chin. J. Chem. Eng. 2018, 26, 2023-2033.

5. Li, X.; Zhao, Y.; Qin, B.; Zhang, X.; Wang, Y.; Zhu, Z. Optimization of Pressure-Swing Batch Distillation with and without Heat Integration for Separating Dichloromethane/Methanol Azeotrope Based on Minimum Total Annual Cost. Ind. Eng. Chem. Res. 2017, 56, 4104-4112. [CrossRef]

6. Zhang, Z.; Zhang, Q.; Li, G.; Liu, M.; Gao, J. Design and Control of Methyl Acetate-Methanol Separation Via Heat-Integrated Pressure-Swing Distillation. Chin. J. Chem. Eng. 2016, 24, 1584-1599. [CrossRef]

7. Zhao, L.; Lyu, X.; Wang, W.; Shan, J.; Qiu, T. Comparison of Heterogeneous Azeotropic Distillation and Extractive Distillation Methods for Ternary Azeotrope Ethanol/Toluene/Water Separation. Comput. Chem. Eng. 2017, 100, 27-37. [CrossRef]

8. Li, W.; Zhong, L.; He, Y.; Meng, J.; Yao, F.; Guo, Y.; Xu, C. Multiple Steady-States Analysis and Unstable Operating Point Stabilization in Homogeneous Azeotropic Distillation with Intermediate Entrainer. Ind. Eng. Chem. Res. 2015, 54, 7668-7686. [CrossRef] 
9. Lladosa, E.; Monton, J.B.; Burguet, M. Separation of di-N-Propyl ether and n-Propyl Alcohol by Extractive Distillation and Pressure-Swing Distillation: Computer Simulation and Economic Optimization. Chem. Eng. Process. Process Intensif. 2011, 50, 1266-1274. [CrossRef]

10. Shen, W.; Benyounes, H.; Gerbaud, V. Extension of Thermodynamic Insights on Batch Extractive Distillation to Continuous Operation. 1. Azeotropic Mixtures with a Heavy Entrainer. Ind. Eng. Chem. Res. 2013, 52, 4606-4622. [CrossRef]

11. Shen, W.; Dong, L.; Wei, S.A.; Li, J.; Benyounes, H.; You, X.; Gerbaud, V. Systematic Design of an Extractive Distillation for Maximum-Boiling Azeotropes with Heavy Entrainers. Aiche J. 2015, 61, 3898-3910. [CrossRef]

12. Shen, W.; Benyounes, H.; Gerbaud, V. Extractive Distillation: Recent Advances in Operation Strategies. Rev. Chem. Eng. 2015, 31, 13-26. [CrossRef]

13. Shirsat, S.P. Separation of Isobutyl Alcohol and Isobutyl Acetate by Extractive Distillation and Pressure-Swing Distillation: Simulation and Optimization. Sep. Purif. Technol. 2015, 154, 366. [CrossRef]

14. Wang, Y.; Cui, P.; Ma, Y.; Zhang, Z. Extractive Distillation and Pressure-Swing Distillation for THF/Ethanol Separation. J. Chem. Technol. Biotechnol. 2015, 90, 1463-1472. [CrossRef]

15. Fulgueras, A.M.; Poudel, J.; Kim, D.S.; Cho, J. Optimization Study of Pressure-Swing Distillation for the Separation Process of a Maximum-Boiling Azeotropic System of Water-Ethylenediamine. Korean J. Chem. Eng. 2015, 33, 46-56. [CrossRef]

16. Suo, X.; Ye, Q.; Li, R.; Dai, X.; Yu, H. The Partial Heat-Integrated Pressure-Swing Reactive Distillation Process for Transesterification of Methyl Acetate with Isopropanol. Chem Eng. Process. Process Intensif. 2016, 107, 42-57. [CrossRef]

17. Luo, B.; Feng, H.; Sun, D.; Zhong, X. Control of Fully Heat-Integrated Pressure Swing Distillation for Separating Isobutyl Alcohol and Isobutyl Acetate. Chem. Eng. Process. Process Intensif. 2016, 110, 9-20. [CrossRef]

18. Luyben, W.L. Methanol/Trimethoxysilane Azeotrope Separation Using Pressure-Swing Distillation. Ind. Eng. Chem. Res. 2014, 53, 5590-5597. [CrossRef]

19. Wang, Y.; Cui, P.; Zhang, Z. Heat-Integrated Pressure-Swing-Distillation Process for Separation of Tetrahydrofuran/Methanol with Different Feed Compositions. Ind. Eng. Chem. Res. 2014, 53, 7186-7194. [CrossRef]

20. Zhang, H. Heat Integration Process for Separating System of Toluene and N-Butyl Alcohol with Pressure Swing Distillation; University of Science and Technology: Qingdao, China, 2015.

21. Zhang, Q. Dynamics and Control of Pressure Swing Distillation Process for Azeotropic Systems of Methanol/Ethanol-Tetrahydrofuran Qingdao; University of Science and Technology: Qingdao, China, 2015.

22. Hosgor, E.; Kucuk, T.; Oksal, I.N.; Kaymak, D.B. Design and Control of Distillation Processes for Methanol-Chloroform Separation. Comput. Chem. Eng. 2014, 67, 166-177. [CrossRef]

23. Zhang, Q.; Peng, J.; Zhang, K. Separation of an Azeotropic Mixture of Dimethyl Carbonate and Methanol Via Partial Heat Integration Pressure Swing Distillation. Asia Pac. J. Chem. Eng. 2017, 12, 50-64. [CrossRef]

24. Luyben, W.L. Design and Control of Distillation Systems for Separating Azeotropes; John Wiley \& Son: Hoboken, NJ, USA, 2008.

25. Cao, Y.; Li, M.; Wang, Y.; Zhao, T.; Li, X.; Zhu, Z.; Wang, Y. Effect of Feed Temperature on Economics and Controllability of Pressure-Swing Distillation for Separating Binary Azeotrope. Chem. Eng. Process. Process Intensif. 2016, 110, 160-171. [CrossRef]

(C) 2019 by the authors. Licensee MDPI, Basel, Switzerland. This article is an open access article distributed under the terms and conditions of the Creative Commons Attribution (CC BY) license (http://creativecommons.org/licenses/by/4.0/). 